\title{
Phylogeny with introgression in Habronattus jumping spiders (Araneae: Salticidae)
}

\author{
Geneviève Leduc-Robert ${ }^{1}$ and Wayne P. Maddison ${ }^{1,2^{*}}$ (D)
}

\begin{abstract}
Background: Habronattus is a diverse clade of jumping spiders with complex courtship displays and repeated evolution of $Y$ chromosomes. A well-resolved species phylogeny would provide an important framework to study these traits, but has not yet been achieved, in part because the few genes available in past studies gave conflicting signals. Such discordant gene trees could be the result of incomplete lineage sorting (ILS) in recently diverged parts of the phylogeny, but there are indications that introgression could be a source of conflict.
\end{abstract}

Results: To infer Habronattus phylogeny and investigate the cause of gene tree discordance, we assembled transcriptomes for 34 Habronattus species and 2 outgroups. The concatenated $2.41 \mathrm{Mb}$ of nuclear data (1877 loci) resolved phylogeny by Maximum Likelihood (ML) with high bootstrap support (95-100\%) at most nodes, with some uncertainty surrounding the relationships of H. icenoglei, H. cambridgei, H. oregonensis, and Pellenes canadensis. Species tree analyses by ASTRAL and SVDQuartets gave almost completely congruent results. Several nodes in the ML phylogeny from $12.33 \mathrm{~kb}$ of mitochondrial data are incongruent with the nuclear phylogeny and indicate possible mitochondrial introgression: the internal relationships of the americanus and the coecatus groups, the relationship between the altanus, decorus, banksi, and americanus group, and between H. clypeatus and the coecatus group. To determine the relative contributions of ILS and introgression, we analyzed gene tree discordance for nuclear loci longer than $1 \mathrm{~kb}$ using Bayesian Concordance Analysis (BCA) for the americanus group (679 loci) and the VCCR clade (viridipes/ clypeatus/coecatus/roberti groups) (517 loci) and found signals of introgression in both. Finally, we tested specifically for introgression in the concatenated nuclear matrix with Patterson's $D$ statistics and $D_{\text {FOIL. }}$. We found nuclear introgression resulting in substantial admixture between americanus group species, between $\mathrm{H}$. roberti and the clypeatus group, and between the clypeatus and coecatus groups.

Conclusions: Our results indicate that the phylogenetic history of Habronattus is predominantly a diverging tree, but that hybridization may have been common between phylogenetically distant species, especially in subgroups with complex courtship displays.

Keywords: Phylogeny, Introgression, Hybridization, Transcriptome, Jumping spiders, Salticidae, Salticinae, Plexippini, Harmochirina, Habronattus

\footnotetext{
* Correspondence: wayne.maddison@ubc.ca

${ }^{1}$ Department of Zoology, University of British Columbia, Vancouver, BC V6T

1Z4, Canada

${ }^{2}$ Department of Botany and Beaty Biodiversity Museum, University of British

Columbia, Vancouver, BC V6T 1Z4, Canada
}

(c) The Author(s). 2018 Open Access This article is distributed under the terms of the Creative Commons Attribution 4.0 International License (http://creativecommons.org/licenses/by/4.0/), which permits unrestricted use, distribution, and reproduction in any medium, provided you give appropriate credit to the original author(s) and the source, provide a link to the Creative Commons license, and indicate if changes were made. The Creative Commons Public Domain Dedication waiver (http://creativecommons.org/publicdomain/zero/1.0/) applies to the data made available in this article, unless otherwise stated. 


\section{Background}

The visually-acute jumping spiders include Habronattus, a clade of about 100 described species whose colourful and diverse courtship displays are among the most complex found in arthropods [1-6]. The group is emerging as a model to study the role of sexual selection in divergence $[4,7-11]$, the evolution of sex chromosomes [12, 13], and arthropod visual systems [14-16].

Although these studies of characters and diversification in Habronattus have been guided by our knowledge of the group's phylogeny, their ability to clearly trace evolutionary processes in this densely diverse group has been limited by poor phylogenetic resolution. Several subclades were recognized by distinctive structures and behaviours by Griswold [3] and confirmed by molecular data from two gene regions (nuclear Ef1- $\alpha$ and mitochondrial 16S-ND1, [5]). These include a large clade of 42 species whose males have fringed first legs and modified third legs (here called the VCCR clade, subdivided into the viridipes, coecatus, clypeatus, and roberti groups), the americanus group, the dorotheae group, and several groups of robust-bodied, often shrubdwelling species (agilis, amicus, tranquillus groups, collectively named here the AAT clade). Other wellsupported groups, such as the decorus group, emerged only with molecular data [5]. However, relationships within and among these species groups are, for the most part, little resolved (see, e.g., the conservative tree of Figure 4 in [12]).

Difficulties in resolving Habronattus phylogeny may stem from the recency of its diversification - possibly less than 5 million years (Figure 8 in [17]) - yielding insufficient sequence divergence or high rates of incomplete lineage sorting (ILS, [18]). Maddison and Hedin's [5] gene trees show several cases of distinct morphospecies intermingling when represented by multiple specimens (e.g., $H$. pyrrithrix, $H$. virgulatus, and other coecatus group members). In addition, the recency of their divergence may leave Habronattus species susceptible to hybridization $[19,20]$, leading to introgression and thus discordant phylogenetic signals.

Indeed, signals of introgression have been noted in mitochondrial data between sympatric and closely related species [21] and even between distant species whose courtship ornaments and genitalia differ markedly [5]. Hints are also seen in sexually selected ornaments in males from divergent $H$. pugillis populations, whose patterns of convergence could be explained by introgression [4]. Hybrid zones are known among several pairs of closely-related species ([36], unpublished observations). The possibility of introgression is supported by behavioural studies, which have found that females from different populations of $H$. pugillis have preferences for foreign males with divergent courtship displays, a possible result of antagonistic coevolution between the sexes [7]. If this has happened throughout Habronattus, then we may be faced with an unfortunate irony: the very processes of sexual selection that make this group so tempting to study may at the same time obscure the phylogenetic history we depend on for comparative analyses.

To whatever extent a divergent phylogeny exists in the group, our goal here is to use genomic data to resolve it. We also seek to determine whether the previouslyinferred mitochondrial introgression in Habronattus stands alone as in other taxa (e.g., [23]) or is accompanied by nuclear introgression. Such introgression could do more than confuse phylogeneticists; it could have introduced new genetic variation at a rate faster than possible by mutation alone, leading to the sharing of adaptive loci across lineages and facilitating diversification [24-26]. Although introgression of courtship traits into established systems of mate choice with such elaborate signals might seem difficult, sensory bias, Fisherian runaway, and antagonistic coevolution models could all promote this dynamic [7, 9, 27, 28]. Determining how much genetic discordance in Habronattus can be attributed to introgression may provide crucial insights into whether hybridization may have had any substantial creative role in the group's diversification.

The importance of introgression in animal evolution is uncertain [29], in part because distinguishing discordant signals resulting from ILS and introgression is difficult without phylogenomic datasets [30-33]. We collected transcriptome data for 34 Habronattus species and two outgroups, the first genomic dataset assembled for salticid spiders. With a well-resolved phylogenetic tree, we were then able to use a phylogenetic approach to characterize nuclear and mitochondrial introgression in the group. We focused on the americanus group and the VCCR clade, two of the most diverse clades within Habronattus. To investigate nuclear introgression, we first conducted a Bayesian Concordance Analysis [33, 34] to investigate discordance (caused by either ILS and/or introgression) in gene trees, and we then applied Patterson's D statistic [32] and $\mathrm{D}_{\text {FOIL }}$ [22] tests to explicitly test allele patterns for introgression. We were able to resolve most nodes of the phylogeny with high support and identified several instances of hybridization in the group.

\section{Methods}

\section{Taxon sampling}

We sampled a total of 36 species, including representatives from most major clades within Habronattus, and 2 outgroups (Table 1). We sampled more extensively in species-rich groups (i.e., viridipes/clypeatus/coecatus group, and the americanus group), and prioritized the 
Table 1 Specimens of Habronattus and outgroups sequenced

\begin{tabular}{|c|c|c|c|c|}
\hline \multirow{2}{*}{$\frac{\text { Species }}{\text { Outgroups }}$} & \multicolumn{2}{|l|}{ Voucher } & \multicolumn{2}{|l|}{ Locality, with latitude and longitude } \\
\hline & & & & \\
\hline Evarcha proszynskii Marusik \& Logunov, 1998 & GLR135 & 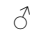 & Canada: BC: Mission & $49.166,-122.409$ \\
\hline Pellenes canadensis Maddison 017 & GLR106 & 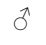 & Canada: BC: Mt. Baldy Road & $49.1135,-119.2103$ \\
\hline \multicolumn{5}{|l|}{ AAT Clade } \\
\hline Habronattus conjunctus (Banks, 1898) & GLR234 & 0 & U.S.A.: AZ: Madera Canyon & $31.7417,-110.8847$ \\
\hline H. hirsutus (Peckham \& Peckham, 1888) & GLR080 & $\hat{\sigma}$ & Canada: BC: Mt. Kobau Road & $49.095,-119.610$ \\
\hline H. signatus (Banks, 1900) & - & - & U.S.A.: CA: Ocotillo & $32.7421,-115.9949$ \\
\hline H. ustulatus (Griswold, 1979) & - & - & U.S.A.: CA: Boulder Oaks & $32.7302,-116.4607$ \\
\hline \multicolumn{5}{|l|}{ americanus group } \\
\hline H. aestus Maddison 2017 & GLR287 & q & México: Sonora: Puerto Peñasco & $31.418,-113.626$ \\
\hline H. americanus (Keyserling, 1885) & GLR014 & 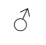 & Canada: BC: Iona Beach & $49.221,-123.214$ \\
\hline H. ophrys Griswold, 1987 & GLR023 & 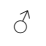 & Canada: BC: Iona Beach & $49.221,-123.214$ \\
\hline H. ophrys & GLR015 & q & Canada: BC: Iona Beach & $49.221,-123.214$ \\
\hline H. sansoni (Emerton, 1915) & GLR066 & $\hat{0}$ & Canada: BC: Kelowna & $49.954,-119.398$ \\
\hline H. tarsalis (Banks, 1904) & GLR297 & 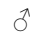 & U.S.A.: AZ: Yuma & $32.731,-114.612$ \\
\hline \multicolumn{5}{|l|}{ DTB clade } \\
\hline H. altanus (Gertsch, 1934) & GLR180 & $\hat{0}$ & Canada: AB: Smoky Lake & $54.112,-112.198$ \\
\hline H. chamela Maddison 2017 & GLR352 & $\hat{0}$ & México: Jalisco: Chamela & $19.5038,-105.0334$ \\
\hline H. decorus (Blackwall, 1846) & GLR132 & 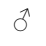 & Canada: BC: Mission & $49.166,-122.409$ \\
\hline H. zapotecanus Griswold, 1987 & GLR339 & 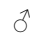 & México: Jalisco: Chamela & $19.5316,-105.0707$ \\
\hline \multicolumn{5}{|l|}{ roberti group } \\
\hline H. roberti Maddison 2017 & JAL14-9281 & 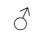 & México: Jalisco: Chamela & $19.496,-105.042$ \\
\hline \multicolumn{5}{|l|}{ viridipes group } \\
\hline H. calcaratus maddisoni Griswold, 1987 & GLR321 & 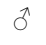 & Canada: ON: Haileybury & $47.45,-79.708$ \\
\hline H. jucundus (Peckham \& Peckham, 1909) & GLR320 & 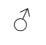 & U.S.A.: OR: Bolan Lake, & $42.024,-123.461$ \\
\hline \multicolumn{5}{|l|}{ clypeatus group } \\
\hline H. aztecanus (Banks, 1898) & GLR347 & 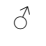 & México: Jalisco: Puerto Vallarta & $20.670,-105.274$ \\
\hline H. clypeatus (Banks, 1895) & GLR227 & $\hat{\sigma}$ & U.S.A.: AZ: Mt. Hopkins Road & $31.686,-110.975$ \\
\hline H. gilaensis Maddison \& Maddison 2016 & AS56 & q & U.S.A.: New Mexico: Silver City & \\
\hline \multicolumn{5}{|l|}{ coecatus group } \\
\hline H. borealis (Banks, 1895) & GLR040 & $\hat{0}$ & Canada: ON: Burlington & $43.33,-79.8$ \\
\hline H. captiosus (Gertsch, 1934) & GLR356 & q & Canada: AB: Guy & $55.4505,-117.1440$ \\
\hline H. empyrus Maddison 2017 & GLR282 & 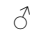 & México: Sonora: Puerto Peñasco & $31.293,-113.452$ \\
\hline H. festus (Peckham \& Peckham, 1901) & GLR094 & $\hat{0}$ & Canada: BC: Hayne's Lease & $49.0813,-119.5181$ \\
\hline H. festus & GLR088 & q & Canada: BC: Hayne's Lease & $49.0813,-119.5181$ \\
\hline H. mexicanus (Peckham \& Peckham, 1896) & GLR353 & 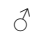 & México: Jalisco: El Tuito & $20.341,-105.350$ \\
\hline H. pyrrithrix (Chamberlin, 1924) & GLR304 & 0 & U.S.A.: AZ: Yuma & $32.731,-114.612$ \\
\hline H. virgulatus Griswold, 1987 & GLR205 & 0 & U.S.A.: AZ: Mt. Hopkins Road & $31.689,-110.975$ \\
\hline \multicolumn{5}{|l|}{ Other Habronattus } \\
\hline H. cambridgei Bryant, 1948 & GLR351 & 0 & México: Jalisco: Puerto Vallarta & $20.670,-105.274$ \\
\hline H. geronimoi Griswold, 1987 & GLR267 & 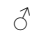 & U.S.A.: AZ: Miller Canyon & $31.416,-110.276$ \\
\hline H. hallani (Richman, 1973) & GLR209 & $0^{2}$ & U.S.A.: AZ: Arivaca & $31.668,-111.245$ \\
\hline H. icenoglei (Griswold, 1979) & GLR283 & $\hat{0}$ & México: Sonora: Puerto Peñasco & $31.273,-113.361$ \\
\hline H. luminosus Maddison 2017 & GLR218 & ㅇ & U.S.A.: AZ: Mt. Hopkins Road & $31.6759,-110.9289$ \\
\hline H. oregonensis (Peckham \& Peckham, 1888) & GLR149 & $\hat{\sigma}$ & Canada: BC: Squamish & $49.8465,-123.1452$ \\
\hline H. paratus (Peckham \& Peckham, 1896) & GLR363 & $\hat{0}$ & Panama: Isla Colon & $9.40376,-79.8635$ \\
\hline H. pugillis Griswold, 1987 & GLR236 & $\widehat{0}$ & U.S.A.: AZ: Mt. Hopkins Road & $31.689,-110.975$ \\
\hline
\end{tabular}


coecatus group because of possible introgression [5]. This is the first phylogenetic analysis to include the species $H$. aestus, $H$. empyrus, and $H$. luminosus [35]. Some of our sampled species were studied by Maddison and Hedin [5] under different names (H. chamela, H. gilaensis, $H$. roberti; see $[35,36])$. The outgroup Pellenes canadensis is closely related to Habronattus within the subtribe Harmochirina, while Evarcha proszynskii is more distantly related, in the neighboring subtribe Plexippina $[17,37]$.

Specimens were collected from 2012 to 2014 from the locations listed in Table 1, following institutional and governmental regulations. Permits for specimens from Mexico were granted through the collaboration of Dr. Tila María Perez by the Secretaría de Medio Ambiente y Recursos Naturales (Semarnat), Mexico. Adult male specimens were preferred because they are easier to identify morphologically to species. We resorted to adult females for $H$. aestus, $H$. luminosus, $H$. captiosus, and $H$. gilaensis because males were not available, but in each case there are no sympatric closely related species likely to be confused with them, and males have been collected from the same locations. Both a male and a female specimen were included for $H$. ophrys and $H$. festus in an effort to assemble a more complete reference transcriptome.

DNA of $H$. paratus was preserved in 95\% EtOH. All other specimens were killed by submersion in RNAlater for RNA preservation. To maximize tissue exposure, the cephalothorax and abdomen were opened immediately upon submersion. All specimens were stored at $-20{ }^{\circ} \mathrm{C}$. Legs and the male palps or the female epigynum were preserved separately as vouchers (stored at the Beaty Biodiversity Museum at the University of British Columbia, Table 1).

\section{Molecular extractions and sequencing}

Total RNA was extracted from whole specimens using a combination of TRIzol extraction (Life Technologies) and RNeasy Mini Kit (Qiagen) for RNA purification and DNAse digestion. DNA was extracted from the legs and abdomen of $H$. paratus using a QIAamp DNA Investigator Kit (Qiagen), assessed for integrity on a 21,000 Bioanalyzer. Libraries were constructed with BIO-O NEXTflex Library Prep Kits (Bioo Scientific, Inc.) with insert sizes averaging $220 \mathrm{bp}$ for RNA and $300 \mathrm{bp}$ for DNA, and sequenced as $100 \mathrm{bp}$ paired-end reads on an Illumina HiSeq 2000 (Illumina, Inc.) at the Biodiversity Research Centre Next Generation Sequencing Facilities (University of British Columbia). For economic feasibility we chose a strategy of building a de novo assembled transcriptome for one of two species that were deeply sequenced $(H$. ophrys and $H$. festus), then assembling the other species by reference to it, allowing them to be less deeply sequenced. For the latter species, we aimed for at least 20 million paired reads per species before trimming, and achieved 5-30 million reads after trimming (see Additional file 1: Table S1 for sequencing summary). Marshal Hedin supplied sequence reads of transcriptomes of $H$. signatus and $H$. ustulatus, prepared and sequenced as 50 bp paired end sequences, and Megan Porter supplied sequence reads of $H$. gilaensis, prepared and sequenced as 150 bp paired end sequences. Sequence reads are deposited in the Sequence Read Archive (SRA submission SUB3319693 [38]); accession numbers are in Additional file 1: Table S1.

\section{Sequence read filtering and trimming}

Any sequence read with an average Phred score under $\mathrm{Q}=30$ was discarded. All remaining reads were quality checked with FASTQC V0.10.1 [39]. Terminal nucleotides were trimmed using fastq-mcf from ea-utils [40] if they had a score below $\mathrm{Q}=30$ or if they were sequencing adaptors. Reads that were $95 \%$ or more homopolymer were discarded and any suspected contaminants, detected from the GC content curve of FASTQC, were trimmed using PRINSEQ-lite [41]. Any read shorter than $33 \mathrm{bp}$ after trimming was discarded.

\section{Reference transcriptome}

Transcriptomes were assembled de novo for $H$. festus and H. ophrys in Trinity RNA-seq_v20140717 [42] with the command: "Trinity.pl -seqType fq -left leftreads.fq -right rightreads.fq --JM 110G -CPU 12 -inchworm_cpu 12 -bflyCPU 12 -min_contig_length 200 --kmer_cov 2".

Both assemblies were similar in size and quality, so we selected $H$. ophrys as the reference transcriptome because of predicted ease of obtaining this species for future studies.

We filtered the approximately 100,000 transcripts from $H$. ophrys prior to using its transcriptome as a reference for subsequent assemblies. We determined transcript abundance with RSEM v1.2.19 [43] and kept only the most abundant transcript variant per gene. Any remaining redundant transcripts identified with CDHIT-EST [44] with a similarity threshold of $95 \%$ were removed (176 transcripts removed). To decrease the likelihood of paralogous genes assembling on a reference transcript during reference-based assemblies, we conducted an all-versus-all BLAST with all remaining $H$. ophrys contigs and removed any contig with a contig other than itself as a significant hit (blastx, evalue $=10^{-3}$; 34 transcripts removed). To set codon positions, the reference transcriptome was scanned for open reading frames using TransDecoder_r20131110 [42] and the longest open reading frame of a transcript was chosen as its protein coding region. If multiple non-overlapping 
coding regions were found on a transcript, those transcripts were split between coding regions.

We conducted a BLAST search of the entire $H$. ophrys transcriptome (evalue $=10^{-3}$, min. HSP length $=33$, max_target_seqs $=20$ ) to the $H$. oregonensis mitochondrial genome [45] and any significant hits were removed from the final reference nuclear transcriptome. The annotated $H$. oregonensis mitochondrial genome [45], was used instead as the reference for all mitochondrial assemblies.

\section{Reference-based assembly of transcriptomes}

For every species (including reference species H.ophrys), sequencing reads were first mapped to the $H$. oregonensis mitochondrial genome and the remaining unmapped reads were mapped to the reference transcriptome using CLC Genomics Workbench (CLC Bio), chosen because of its extensive facilities for making and visualizing reference-based assemblies. Reads of $H$. ophrys were also remapped to its own reference so as to obtain sequencing depth information and follow a trimming protocol comparable to the other species. Assembly parameters used were: mismatch $\operatorname{cost}=2$, insertion $\operatorname{cost}=3$, deletion cost $=3$, length fraction $=0.5$, similarity fraction $=0.8$. When consensus sequences were extracted from the read mappings, polymorphisms were retained as ambiguity codes in the consensus sequence if the variant represented $30 \%$ or more of mapped alleles, except for $H$. festus which used a combination of read count and sum of quality scores to resolve the base conflict. Nuclear sequences with average sequencing depth less than $5 x$ were discarded, and contigs were split into fragments at any region where sequencing depth was less than $5 \times$. Following these steps, only contigs longer than $200 \mathrm{bp}$ were retained. Total raw sequencing reads, trimmed sequencing reads, the number of reads assembled, total transcripts, and sequencing depth are summarized for every species in Additional file 1: Table S1. Only mitochondrial data were used for $H$. paratus, as most of its nuclear sequences were incomplete or with inadequate sequencing depth.

\section{Alignment and filtering of loci}

We converted species-based FASTA files into locusbased FASTA files and trimmed sequences of any remaining poly-A or poly- $\mathrm{T}$ tails using custom python scripts. If a locus was fragmented into multiple sequences for a species, and the lengths of those fragments when added together met our length cut-off (200 bp), then those sequence fragments were scaffolded using their positions aligned against the reference transcript, filling in with "N"s to represent the missing data.

At this stage, there were 55,316 loci, most present only in the two species with a much higher number of reads,
$H$. ophrys and H. festus. Of those, 7132 were present in at least 15 species, and 4188 were present in at least 25 species. Each locus was aligned using MAFFT v7.058b [46] using L-INS-I and parameters -localpair -maxiterate 100 . Alignments of a few loci were manually corrected to resolve obvious reading frame misalignments. Nucleotides trailing from either end of an alignment (present in $30 \%$ or less of species) were trimmed and a sequence was discarded if it was $30 \%$ or less than the average sequence length for that alignment. All alignment, trimming and partitioning steps were completed with the aid of Mesquite 3.02 [47], with a few steps involving the package Gataga (Maddison and Maddison, unpubl.).

The aligned matrix for each locus was partitioned by codon position or non-coding based on Transdecoder results. To better understand the cause of gaps and ambiguous nucleotides in these alignments, we aligned a subset of loci with annotated sequences with known protein-coding regions matched using a BLAST search to the SWISS-PROT database, to Ef1- $\alpha$ [5], and to the annotated mitochondrial genome [45]. All sites with gaps were caused by an insertion of a nucleotide in one or a few sequences, implying highly unlikely frame-shifts in conserved genes. These insertions occurred only in the reference-based assemblies and never occurred in the (higher quality) reference sequence. Therefore, we inferred that these insertions of gaps and nucleotides were assembly errors rather than true insertions. As a result, columns with gaps were excluded whenever coding-region gaps were not present in the reference sequence (to avoid any frameshift mutations). In noncoding regions there were also occasionally insertions in some species - in the vast majority of columns, in only one or two species, again suggesting assembly errors. However, a more relaxed exclusion criterion was used for non-coding regions: a column was excluded if the insertion was present in less than $50 \%$ of species.

Some loci showed high levels of ambiguous sites, which might not represent true heterozygosity, but rather multiple transcript variants or paralogs assembled on the same reference transcript. To be conservative, loci were excluded from analyses if ambiguous sites constituted more than $3 \%$ of the alignment. 236 loci were thereby removed, resulting in 1877 loci in our highest quality subset (present in at least 25 species, at least $200 \mathrm{bp}$ long, with a coding region identified by Transdecoder, and with less than $3 \%$ ambiguity).

Because reference-based assemblies generate sequences aligned to the same reference transcripts, sequences assembled on the same reference are treated as orthologous. Filtering for paralogs in the H. ophrys reference transcriptome, reducing reference transcriptome redundancy, and removing sequences with high levels of 
ambiguous sites are expected to have reduced the possibility of paralogs. To assess whether there were obvious paralogs, gene trees were constructed for all genes of alignment lengths over $1 \mathrm{~kb}$ with a single search replicate in RAxML 7.7.9 [48]. None of the trees produced had unusually long branches or phylogenetic structures obviously indicative of paralogy. While this reassures us that there were not deep paralogs, some more recent paralogs may have passed through our filters. Our expectation is, however, that the effect of paralogs averaged over many loci would be to add noise rather than systematic biases, as noted in the discussion about introgression and artifacts.

\section{Nuclear subsets}

We separated the nuclear loci into four groups. The first group, the Primary Subset, included the 1877 highest quality loci as described above (2.41 Mb alignment; average of 2,036,173 base pairs per species). These were used for our primary nuclear phylogenetic analyses. Among the remnant "low quality" loci, those matching the criteria of high quality except for being present in only 15 to 24 species were treated as the second group, the Missing Species (MS) subset (1019 loci; average of 548,107 bp per species). The other remnants without an identifiable coding region but present in 25 or more species were the third group, the Noncoding Loci (NL) subset (236 loci; average of 92,567 bp per species). The fourth group consisted of loci not meeting any of these criteria; they were discarded.

\section{Mitochondrial data}

To compose a complete mitochondrial alignment, sequences for 16S RNA (1022 bp), 12S RNA (691 bp), ND1 (921 bp), ND2 (959 bp), ND3 (342 bp), ND4 (1289 bp), ND4L (268 bp), ND5 (1638 bp), ND6 (429 bp), ATP6 (666 bp), ATP8 (158 bp), Cytochrome B (1111 bp), COX1 (1542 bp), COX2 (666 bp), COX3 (786 bp) were aligned, concatenated, and assigned codon positions based on annotations from the $H$. oregonensis mitochondrial genome [45]. This yielded the concatenated mitochondrial matrix, with a total alignment length of $12.33 \mathrm{~kb}$.

Maddison and Hedin's [5] two-gene Habronattus phylogeny includes many species absent in our transcriptome data. In order to get a denser perspective on mitochondrial introgression within the VCCR clade, we took sequences from the 16SND1 region from our mitochondrial data (1047 bp) for our 35 transcriptome species and DNA specimen $H$. paratus, and added to them data for the same region obtained by Maddison and Hedin [5], Masta and Boore [45], and Masta and Maddison [11]. Combined these yielded a matrix with 196 sequences of 16SND1 from across the genus, including 37
VCCR species (in comparison to 13 species in our transcriptome data).

\section{Phylogenetic analyses}

Habronattus species phylogeny from nuclear genes was inferred by maximum likelihood from concatenated alignments, as well as by coalescent-based methods (ASTRAL, SVDQuartets).

\section{Maximum likelihood on concatenated matrices}

All maximum likelihood phylogenetic searches on the concatenated matrices were run in RAxML 7.7.9 [48] with 20 search replicates for the ML tree, and one search replicate for each of the 1000 bootstrap replicates. We used PartitionFinder (v.1.1.1 [49]) to assess the substitution models, using a greedy algorithm search and AIC model selection, and considering both locus and codon positions as possible partitioning criteria.

In addition to the primary concatenated matrix of 1877 genes, 12 other matrices were analyzed representing different subsets of nuclear loci, to explore the consistency of support. Eight of these were equal subsets of our primary matrix (nuclear subsets 1-8; 302,200 bp each). Locus order was randomized prior to subset division and concatenation to ensure that each subset represents a random sample of loci. In addition, the remnant (low quality) loci were used to make two other disjoint matrices (MS and NL, as defined above).

To assess the strength of the mitochondrial phylogenetic signal with less data, we divided mitochondrial rRNA $(1.72 \mathrm{~kb})$ from protein-coding sites and then separated the protein-coding alignment into 4 even subsets (mtDNA subsets 1-4; $2.53 \mathrm{~kb}$ each).

In the analysis for the expanded 16SND1 matrix we constrained the inference to enforce any node in the concatenated mitochondrial tree that had at least $90 \%$ bootstrap support. We did this so as to take advantage of the strong resolution available for the 36 transcriptome taxa, and to determine how the additional sequences fell on that skeletal constraint tree. Although we performed the analysis across the whole genus, our results focus on the VCCR clade.

\section{Coalescent methods for the species tree}

Using the primary subset of nuclear genes (1877 loci), two methods based on multi-species coalescent models were used to infer the species phylogeny, ASTRAL [50] and SVDQuartets [51]. ASTRAL version 4.7.12 [52] was applied to the 1020 loci from the primary nuclear subset of alignment length at least $1000 \mathrm{bp}$. For each locus, a single gene tree was reconstructed by a simple maximum likelihood search by RAxML (model GTRGAMMAI, unpartitioned), and the set of 1020 gene trees was analyzed by ASTRAL using default settings. For the 
SVDQuartets analysis, PAUP* version 4.0a149 (2016; [53]) was applied to the primary concatenated nuclear matrix (2.41 Mb alignment), default search settings, with 1000 bootstrap replicates.

\section{Analysis of introgression}

To assess signals of introgression in the nuclear data, we examined nuclear signals discordant with the species tree using Bayesian Concordance Analysis (BCA), and tested for introgression using D-statistics.

\section{Bayesian concordance analysis}

We used BCA to assess the extent of nuclear discordance and the possibility of introgression [33, 34]. From a Bayesian sample of gene trees for each locus, BCA derives a primary concordance tree representing the dominant phylogenetic signal (an estimate of the species tree). and secondary concordance factors (CF) indicating substantial support from some genes but discordant with the dominant species tree [33, 34, 54]. While BCA does not test explicitly for introgression, if two conflicting secondary CFs are unequal and their 95\% credibility intervals do not overlap (and therefore are significantly different), introgression may be inferred as a possible cause of discordance because under ILS the CFs for conflicting secondary clades would be expected to be equal [54].

We conducted all Bayesian gene tree searches with MrBayes 3.2.2 [55] with 4 chains (3 cold, 1 hot), 2 runs, and $25 \%$ burn-in. To determine the number of MCMC generations required for convergence, 20 genes were run until convergence (standard deviation of split frequencies <0.01; [56]) as a test. The convergence time ranged from 570,000 to $13,087,000$ and averaged 4,025,500 generations. Based on this, we set the number MCMC generations conservatively at 20,000,000 generations per gene. Codon positions were used as partitions.

BCA analyses were conducted using BUCKy 1.4.3 [57] with 2 runs and 4 chains per analysis. Due to computational limitations, we analyzed only the americanus group and the VCCR clade, and included only genes longer than $1 \mathrm{~kb}$ that were present in all species being analyzed. There were 679 genes included for the americanus group analysis (with $H$. signatus as outgroup) and 517 genes included for the VCCR clade analysis (with $H$. ophrys as outgroup).

For the adjustable prior $\alpha$, the a priori level of gene tree incongruence, we tried values of $\alpha=0.1,1,2,5$ and 10. We found no substantial difference in results using different $\alpha$ for the americanus group, so kept $\alpha$ set to 1 . Analyses involving the VCCR clade had difficulty converging at higher $\alpha$, so $\alpha$ was set to 0.1 for that analysis, although there was very little difference between CFs depending on $\alpha$ for this clade. The americanus group analysis ran for 10,000,000 generations and the VCCR clade analysis ran for $30,000,000$ generations due to the longer time required for convergence.

\section{Patterson's $D$ statistic and $D_{\text {FOIL }}$}

To distinguish incomplete lineage sorting (ILS) and introgression patterns in SNP data, we conducted Patterson's D statistic tests [58] and the related test $\mathrm{D}_{\mathrm{FOIL}}$ [22]. These tests compare patterns of shared SNPs across sets of 4 and 5 taxa, respectively. Under ILS in a 4-taxa binary tree, it is expected that the number of alleles shared by non-sister taxa (i.e. discordant with the species tree) would be equal for each possible non-sister pairing (i.e., patterns ABBA and BABA) [32]. Introgression between two species is inferred when they have significantly more shared alleles than alternative discordant pairs (i.e., more ABBA than BABA or vice versa). The same principle can be applied to a 5-taxa tree with structure (( 1 , species 2),(species 3 , species 4$)$ ), outgroup), with some added complexity [22]. Whether Patterson's D statistic or $\mathrm{D}_{\mathrm{FOIL}}$ was used depended on the structure of the species tree of the taxa being tested.

We tested sets of species based on indications of introgression in previous studies [5], in the mitochondrial phylogeny, or in the BCA. There were 3 principal hypotheses of introgression tested: (1) among species of the americanus group, (2) between $H$. roberti and the other groups of the VCCR clade and (3) between the clypeatus group and coecatus group. In addition, the possibility of very distant introgression between the DTB clade (decorus/texanus/banksi groups), VCCR clade and the americanus group was also explored.

For the americanus group tests, we included all 5 americanus group species. For the other tests, we selected a few species as representatives of each clade. For the $H$. roberti/VCCR D statistics analysis, we used the species with the most sequencing data per clade for the four clades involved $(H$. roberti, and one representative of each of the viridipes, clypeatus, coecatus groups). For the clypeatus group - coecatus group analysis, we did 6 combinations of species, including 2 coecatus group and 2 clypeatus group species per $\mathrm{D}_{\mathrm{FOIL}}$ test, and using $H$. ophrys as the fifth species (outgroup). H. pyrrithrix (coecatus group) was included in each combination because its phylogenetic position is consistent in both the concatenated nuclear and mitochondrial phylogenies; $H$. clypeatus (clypeatus group) was included because of mitochondrial introgression detected in the mitochondrial phylogeny and in other members of its species group by Maddison and Hedin [5]. By using more or less divergent sister taxa in different tests for comparison, we can better approximate where in the coecatus and clypeatus group introgression occurred. Even still, Dstatistics and $\mathrm{D}_{\mathrm{FOIL}}$ cannot rule out the possibility that 
detected introgression was with related lineages that are extinct or were otherwise not sampled (i.e., ghost lineages) [59].

$\mathrm{D}_{\mathrm{FO}}$ was run in mode dfoilalt to reduce noise from synapomorphic sites. We used a custom $\mathrm{R}$ script to count allele patterns. All sites that included ambiguous nucleotides, gaps, or missing data were excluded from the analysis. $\mathrm{D}_{\mathrm{FOIL}}$ estimated divergence $\mathrm{T}$-values were verified against the assumption that $\mathrm{T}_{12}<\mathrm{T}_{34}<\mathrm{T}_{1234}$. Because each $\mathrm{D}_{\mathrm{FOIL}}$ and D-test is a chi-square binomial test, we adjusted significance for multiple comparisons (62 in total, including all $\mathrm{D}_{\mathrm{FOIL}}$ and D tests) with a Bonferroni correction to a $p$-value lower than 0.0008 to indicate $95 \%$ significance.

\section{Results}

\section{Transcriptome assemblies and data filtering}

The unfiltered $H$. ophrys reference transcriptome included 117,859 transcripts (total $53,927,457$ bases assembled), with an N50 (analogous to median contig length; [60]) of 516, and an average sequencing depth of $103 \times$. Following filtering for redundancy, selection of a single variant per gene, removal of possible paralogs, and the separation of connected transcripts, there were 92,343 transcripts left.

Additional file 1: Table S1 gives a summary of transcriptome assemblies, excluding unused sequences with low $(<5 \times)$ sequencing depth. After reads were remapped, 51,143 H.ophrys transcripts had sufficient (5x) sequencing depth (average sequencing depth $111 \times$ ). For all other species, reference-based transcriptome assemblies mapped on average $77 \%$ of trimmed reads to either the nuclear reference transcriptome (average nuclear sequencing depth $=67 x$ ) or mitochondrial reference genome (average mitochondrial sequencing depth $=13,640 \times$ ). There was an average of 10,164 transcripts assembled per species, although numbers ranged widely (depending on the number of reads) from 3746 for $H$. roberti to 28,846 for $H$. festus. Aligned matrices for each of the partitions (Primary, Missing Species, Noncoding Loci, and mitochondrial) are available in Additional file 2.

\section{Substitution model selection}

For the primary concatenated nuclear matrix, PartitionFinder was unable to analyze the approximately 7500 partitions (codon positions for each of 1877 genes) because of computational limits. Thus, we applied it to the mitochondrial genes and on a sample of 20 nuclear genes, using it to assess models rather than choose partitions. GTR + G + I or GTR + G was chosen as the optimal substitution model using AIC for all mitochondrial partitions. For the 20 nuclear genes tested, 33 partitions had a GTR model selected, 22 had TVM, 10 had K81uf, 5 had TIM, 4 had HKY, and 3 had TrN (these number include model variations like $+\mathrm{G}$ or $+\mathrm{I})$. We were unable to set a different model for each partition in concatenated matrices due to computational limitations. Instead, we set GTR + G + I as the substitution model in all maximum likelihood (ML) and Bayesian analyses (nst $=6$ rates $=$ invgamma) because it was the most commonly chosen and most widely applicable mode. We used 4 partitions based on codon position (position 1, position 2, position 3, and noncoding) for all figured analyses. To test whether partitioning played a major role, we also ran an unpartitioned likelihood analysis on the 1877 locus concatenated nuclear matrix, as well as one partitioned by locus.

\section{Nuclear phylogeny}

The nuclear phylogenetic results are summarized in Figs. 1 and 2a; trees are available in NEXUS format in Additional file 3. Most species relationships are resolved with strong support, and concordantly among the concatenated nuclear and species tree analyses. The independent "low quality" remnant matrices also support many of the clades. As suggested by Maddison and Hedin's [5] results from a few genes, Habronattus is divided into the AAT clade (amicus, agilis, and tranquillus groups) and a large clade of the remaining species, within which $H$. geronimoi is sister to the rest. The americanus group and the VCCR clade are also resolved, and within the latter the viridipes, clypeatus and coecatus groups are each monophyletic.

The phylogeny has a few notable regions of uncertainty, which are also points of disagreement among the analyses. Although the previous morphological data (discussed below) provides good support for the monophyly of Habronattus, only one of the 1/8th nuclear partitions supports it here. The concatenated nuclear ML tree, the concatenated bootstrap consensus, three of the $1 / 8$ th partitions, and the ASTRAL tree all place Pellenes canadensis as sister to the AAT clade; the remnant matrices place $P$. canadensis as sister to the major Habronattus clade that excludes the AAT clade, while the SVDQuartets tree weakly places $P$. canadensis as sister to $H$. conjunctus. The clade including the VCCR clade plus $H$. hallani, $H$. pugillis and $H$. luminosus ("VCCR+" clade) is well supported, as is the larger clade that adds $H$. cambridgei, $H$. icenoglei, and $H$. oregonensis. However, the relationships among the latter three are unstable: the concatenated nuclear ML tree chooses (cambridgei, ((icenoglei, oregonensis), $\mathrm{VCCR}+))$, the concatenated bootstrap consensus $(i,((c, o), \mathrm{V}))$, ASTRAL $(c,(i,(o, \mathrm{~V})))$, and SVDQuartets $((c, i),(o, \mathrm{~V}))$, though the last with low bootstrap support. A few discordant placements show up in some analyses (e.g., the SVDQuartets analysis strongly places $H$. tarsalis sister to $H$. americanus and $H$. sansoni, and weakly places $H$. roberti as sister to the 


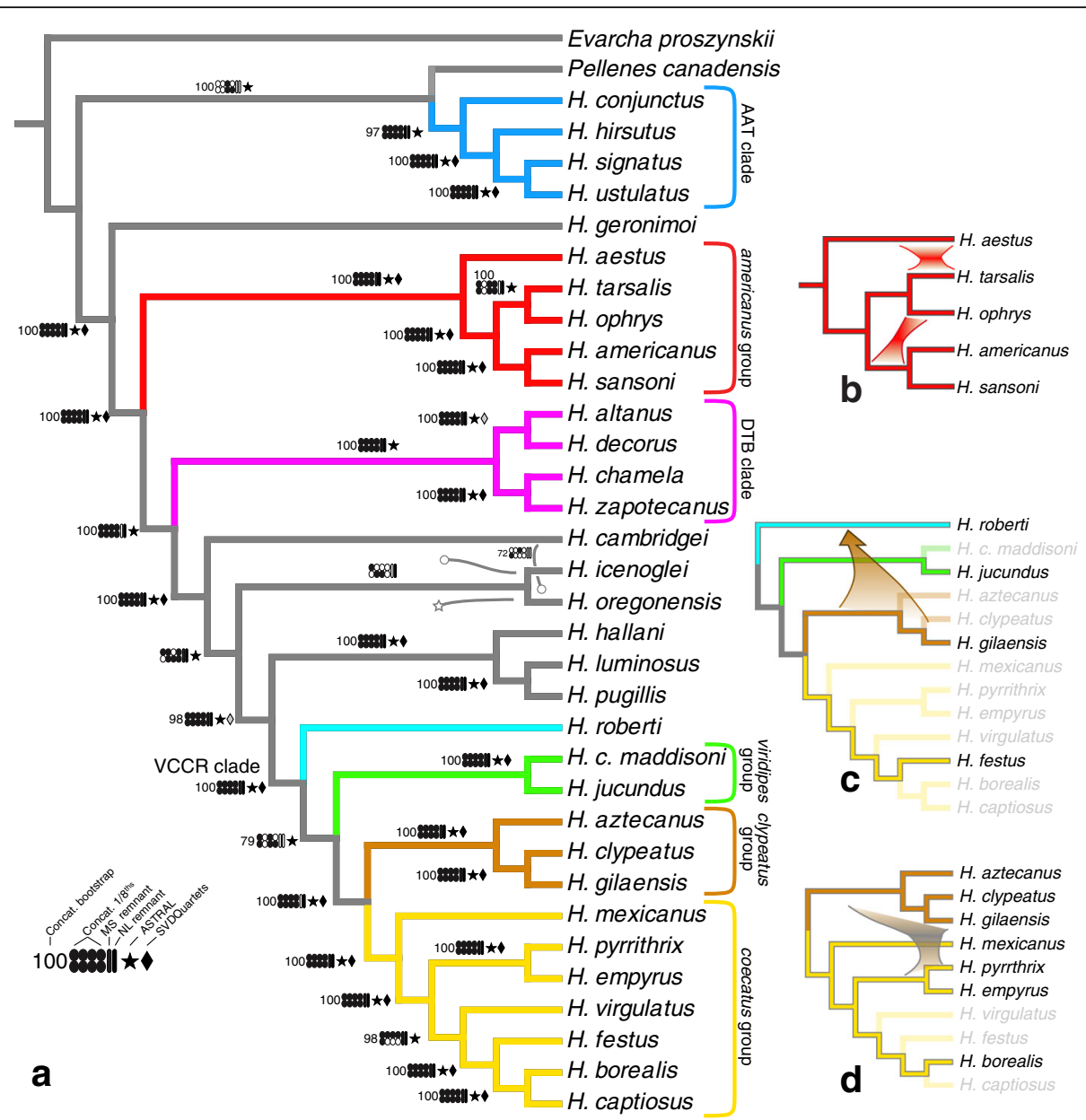

Fig. 1 Species phylogeny from nuclear data in Habronattus (for branch lengths, see Fig. 2a), and main conclusions of nuclear introgression. a Maximum likelihood tree from 1877 concatenated nuclear loci ( $2.41 \mathrm{mb}$ alignment; RAxML); largely concordant with the ASTRAL tree (stars). Colours mark species groups as labeled. Legend for decorations at lower left. Bootstrap percentages for ML analysis of concatenated nuclear matrix. Spots and vertical bars show presence of clade in the ML tree for various partitions of the data (black=clade present). Spots show presence of clade in tree for each of the 1/8th portions of concatenated nuclear loci. Vertical bars show presence of clade in the trees from the remnant Missing Species (MS) and the Noncoding Loci (NL) matrices. Stars show clades present in ASTRAL analysis of 1020 ML gene trees of alignment length at least $1000 \mathrm{bp}$. Diamonds show clades with (black) >94\% or (grey) 75-94\% bootstrap support in SVDQuartets analysis. Discordant results shown by grey arrows with circle (concatenated ML bootstrap consensus) or star (ASTRAL). For instance, the concatenated bootstrap consensus places $\mathrm{H}$. cambridgei as sister to oregonensis, and H. icenoglei in a more basal position with respect to the VCCR clade. From $\mathbf{b}$ to $\mathbf{d}$ : Conclusions of introgression from D-statistics and BCA for $\mathbf{b}$ the americanus group, $\mathbf{c}$ H. roberti and the VCCR clade, and $\mathbf{d}$ the clypeatus and coecatus groups. See text for signals of other introgression events

viridipes group). The unpartitioned $\mathrm{ML}$ analysis of the concatenated nuclear matrix yielded the same topology as in Fig. 1a, but partitioning by locus yielded the close alternative resolution (icenoglei, ((oregonensis, cambridgei), VCCR + ). The primary concordance trees from the BCA analysis in the americanus group and the VCCR clade match those portions of the concatenated nuclear ML tree except for the placement of $H$. virgulatus.

\section{Mitochondrial phylogeny}

The mitochondrial transcriptome tree (Fig. 2b; Additional file 3) is broadly concordant with the nuclear tree, concurring on the VCCR clade, the next larger clade adding $H$. hallani, $H$. pugillis and H. luminosus, and the next larger clade adding $H$. cambridgei, $H$. oregonensis, and $H$. icenoglei. The americanus group is monophyletic, as is the AAT clade. Bootstrap support values are generally high, and some key results are consistent across rRNA and four protein-coding mitochondrial subsets (Fig. 2b). The strongly supported results, however, include several notable differences with the nuclear phylogeny (Fig. 2a), including the placement of the $H$. clypeatus specimen and the relationship of the DTB clade and the americanus group. These will be discussed in the context of introgression. 

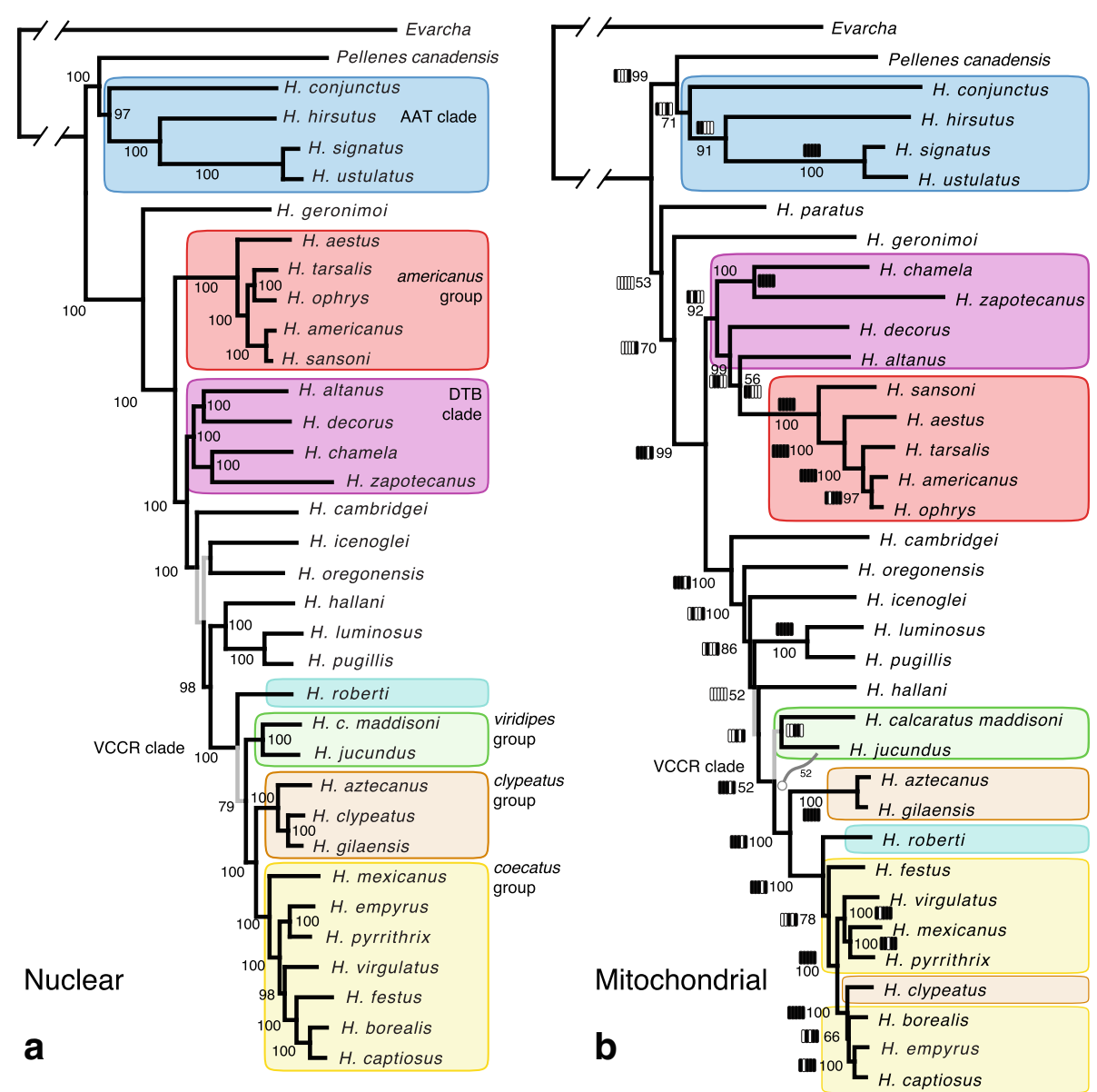

Fig. 2 Comparison of nuclear and mitochondrial phylogenetic results. a Maximum likelihood nuclear tree from the concatenated $2.41 \mathrm{mb}$ alignment, as in Fig. 1, but with branch lengths (RAxML). Named groups shown with same colours as in Fig. 1. Numbers show bootstrap percentages; grey branches with < 95\% bootstrap support. b Maximum likelihood mitochondrial tree from the concatenated $12.33 \mathrm{~kb}$ alignment, with bootstrap percentages (RAXML). Bars show presence of clade in the ML tree for each of five subdivisions of the concatenated matrix (rRNA, followed by 4 portions of coding regions; black= clade present)

The 16SND1 phylogeny (Fig. 3a; Additional file 3) of the VCCR clade, based on a combination of Sanger sequencing data and transcriptome data, generally resolves the groups but not the species. Of the eight species of the coecatus group represented by more than one specimen, only two appear as monophyletic on the tree $(H$. ammophilus, $H$. festus). The clypeatus group is not monophyletic, with three specimens $(H$. cf. arcalorus "CHIH" [HA292]; H. velivolus [HA659]; H. clypeatus [GLR227, transcriptome]) appearing within the coecatus group.

\section{Bayesian concordance analyses}

Key findings from the BCA are summarized in Fig. 4a for the americanus group and Fig. 5a for the VCCR clade. All additional concordance factors $>0.05$ are listed in Additional file 4.

The BUCKy analysis of 679 americanus group loci (Fig. 4a; Additional file 4) converged with an average SD of mean sample-wide CF of $3.24 \times 10^{-5}$ (all 105 topologies represented among the $15 \mathrm{M}$ trees sampled). The analysis supports the same americanus group phylogeny as the concatenated nuclear phylogeny seen in Fig. 1a. $H$. ophrys is linked to $H$. americanus and $H$. sansoni via a $\mathrm{CF}(\mathrm{CF}=0.305, \mathrm{CI}=0.272-0.339)$ that is more than twice the $\mathrm{CF}$ shared for the equivalent pairing $H$. tarsalis and $H$. sansoni $/ H$. americanus $(\mathrm{CF}=0.136, \mathrm{CI}=0.112$ 0.162 ). The $\mathrm{BCA}$ also found significant asymmetric support linking $H$. aestus with $H$. tarsalis $(\mathrm{CF}=0.136, \mathrm{CI}=$ $0.112-0.162)$ compared to the conflicting clade $H$. aestus and H. ophrys $(\mathrm{CF}=0.39, \mathrm{CI}=0.023-0.055)$.

The BUCKy analysis with 517 loci for the VCCR clade (Fig. 5a; Additional file 5) converged with an average SD of mean sample-wide CF of 0.003 (4,795,750 topologies and 8177 distinct splits represented among the $15 \mathrm{M}$ trees sampled). The primary concordance tree (Fig. $3 \mathrm{~b}$ ) from the VCCR-clade analysis is in agreement with the concatenated nuclear phylogeny except for the position 


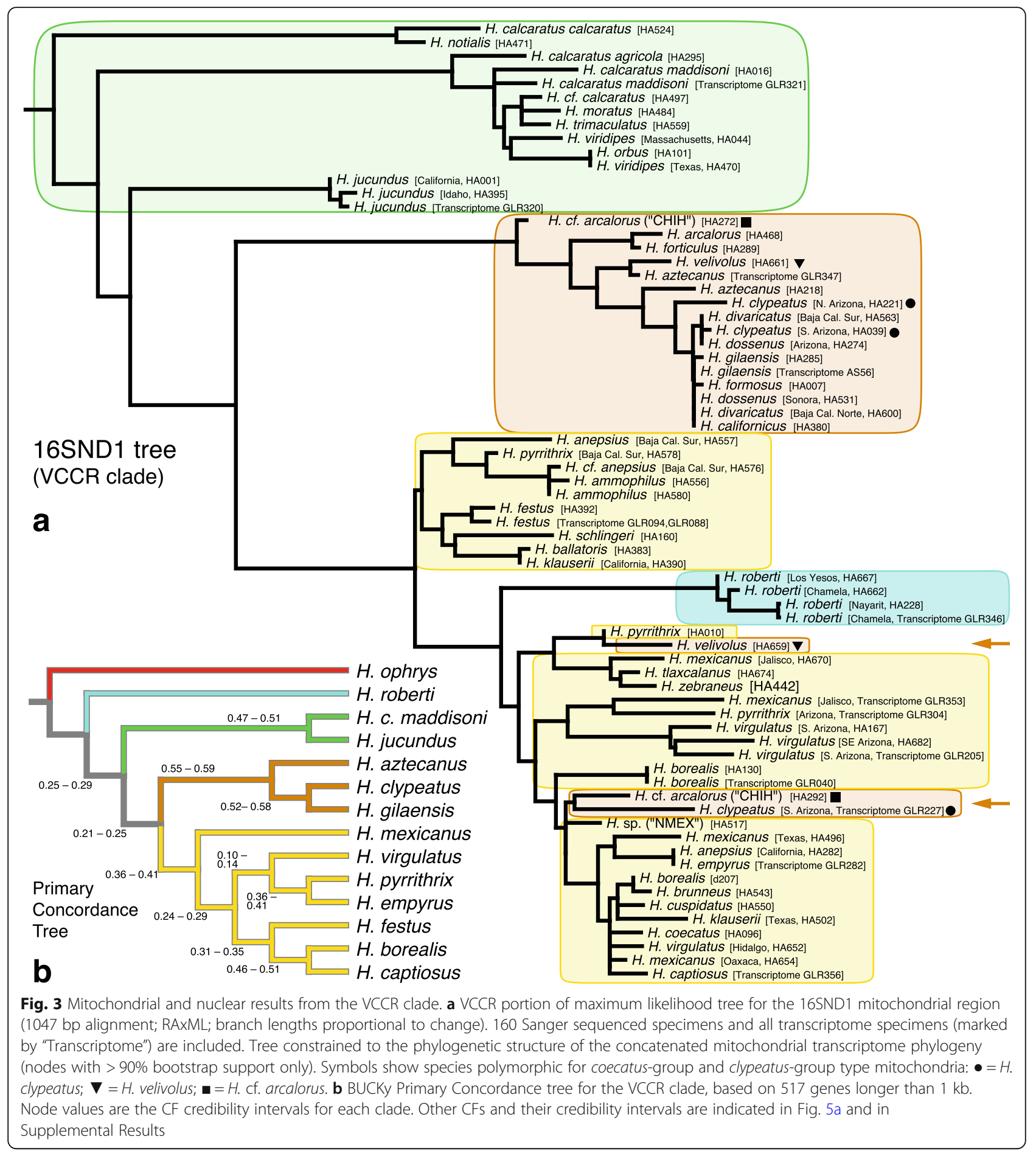

of $H$. virgulatus, though this placement is accompanied by a very low concordance value $(\mathrm{CF}=0.1$ 0.14). Two substantial conflicting (secondary) CFs place $H$. roberti with the clypeatus/coecatus clade $(\mathrm{CF}=0.196, \mathrm{CI}=0.174-0.222)$ and with the clypeatus group $(\mathrm{CF}=0.188, \mathrm{CI}=0.17-0.205)$. Both of these CF credibility intervals are significantly higher than those for alternative conflicting clades: $H$. roberti with the viridipes group $(\mathrm{CF}=0.052, \mathrm{CI}=$ $0.039-0.06)$ and $H$. roberti with the coecatus group $(\mathrm{CF}=0.041, \mathrm{CI}=0.027-0.058)$. There are 35 very small but significant (not overlapping 0) CFs averaging 0.01 linking $H$. clypeatus with particular coecatus group species (see Additional file 5). 


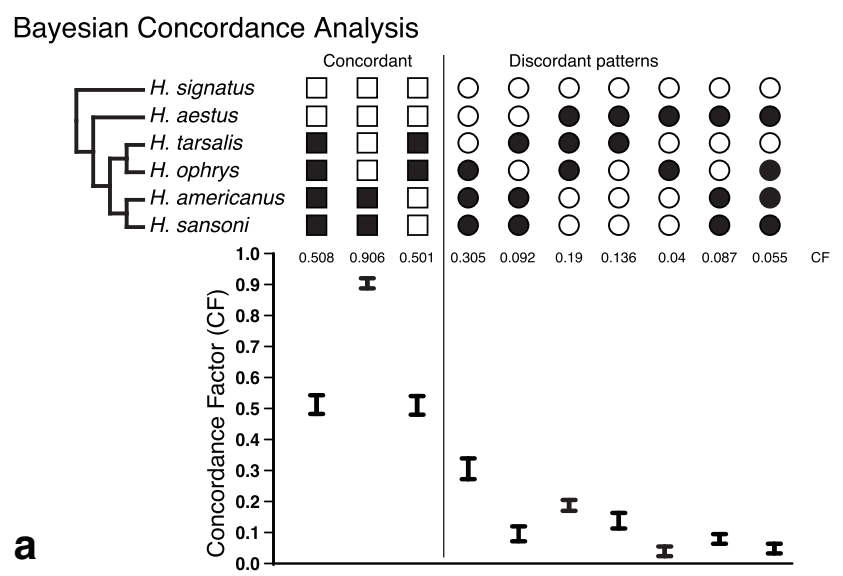

H. ophrys/tarsalis vs. $H$. americanus/sansoni (DFOL)
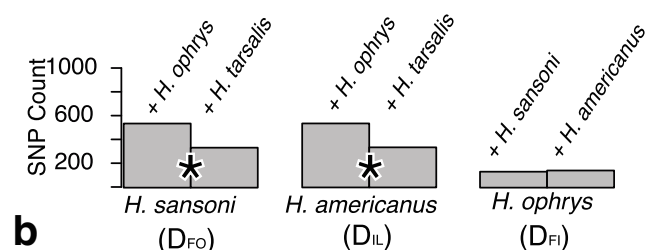

(DFI)

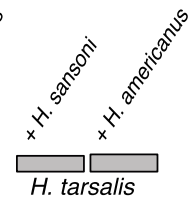

(DoL)

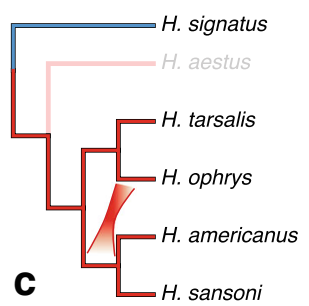

$H$. aestus vs. others (ABBA-BABA)
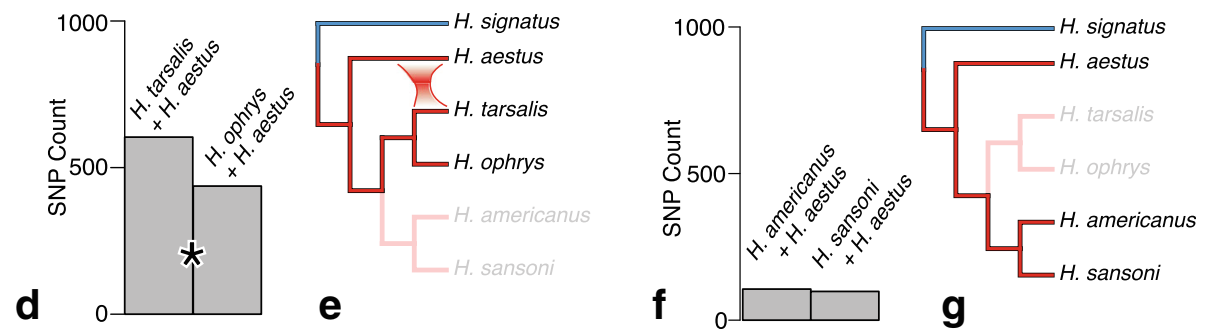

Fig. 4 Signals of nuclear introgression in H. americanus species group (see Fig. 1b for summary interpretation). a BCA analysis using BUCKy, showing concordance factors, using Bayesian sample of trees from 679 loci. Higher CF for the discordant grouping ophrys + americanus + sansoni than tarsalis + americanus + sansoni suggests introgression. $\mathbf{b}$ Total biallelic pattern counts for all $\mathrm{D}_{\mathrm{Foll}}$ tests for introgression between americanus group species; * indicates significant difference at 0.05 level after Bonferroni correction. $\mathbf{c}$ Interpretation of $D_{\text {FOIL: }}$ non-neutral $D_{F O}$ and $D_{\| L}$ values in the D-statistic signature indicate introgression between the ancestor of $\mathrm{H}$. sansoni/H. americanus and $\mathrm{H}$. ophrys. d, $\mathbf{f}$ ABBA vs. BABA allele patterns counts for D statistic tests for introgression in americanus group species; ${ }^{*}$ indicates significant difference at 0.05 level after Bonferroni correction. e, g Interpretation: Introgression is detected between $H$. aestus and $H$. tarsalis (e); none between $H$. aestus and H. americanus/H. sansoni (g). Species not participating in the particular test are greyed

\section{$D_{\text {FOIL }}$ and D-statistics tests of introgression}

Asymmetries of gene-lineage sharing in the americanus group and the VCCR clade are seen also in the $\mathrm{D}_{\mathrm{FOIL}}$ and D statistics (ABBA-BABA) results. Allele counts for these tests are listed in Additional file 6: Table S2 and Additional file 7: Table S4. Results (D values and $p$ values) are reported in Additional file 7: Table S4 and Additional file 8: Table S3.

$\mathrm{D}_{\mathrm{FOIL}}$ tests support introgression between $H$. ophrys and the common ancestor of $H$. sansoni and $H$. americanus (Fig. 4b, $\mathrm{D}_{\mathrm{FO}}=0.232 p<10^{-11}, \mathrm{D}_{\mathrm{IL}}=0.230 p=10^{-11}$, $\left.\mathrm{D}_{\mathrm{FI}}=-0.036 p=0.549, \quad \mathrm{D}_{\mathrm{OL}}=-0.043 p=0.05\right)$.
ABBA-BABA tests detect an introgression signal between $H$. aestus and $H$. tarsalis, whether the fourth species is $H$. ophrys (Fig. $\left.4 \mathrm{~d}, \mathrm{D}=0.160, p<10^{-6}\right), H$. americanus $\left(\mathrm{D}=0.192, p<10^{-10}\right)$, or $H$. sansoni $(\mathrm{D}=$ $\left.0.165, p<10^{-8}\right)$.

Introgression is detected using ABBA-BABA tests between $H$. roberti and $H$. gilaensis (clypeatus group) when the third species used for comparison is $H$. jucundus (viridipes group) (Fig. $5 \mathrm{~b}, \mathrm{D}=-0.405, p<10^{-12}$; interpretation in Fig. 5c) or $H$. festus (coecatus group) (Fig. 5d $\mathrm{D}=0.377, p<10^{-12}$; interpretation in Fig. 5e). Introgression is also detected between $H$. festus (coecatus group) 


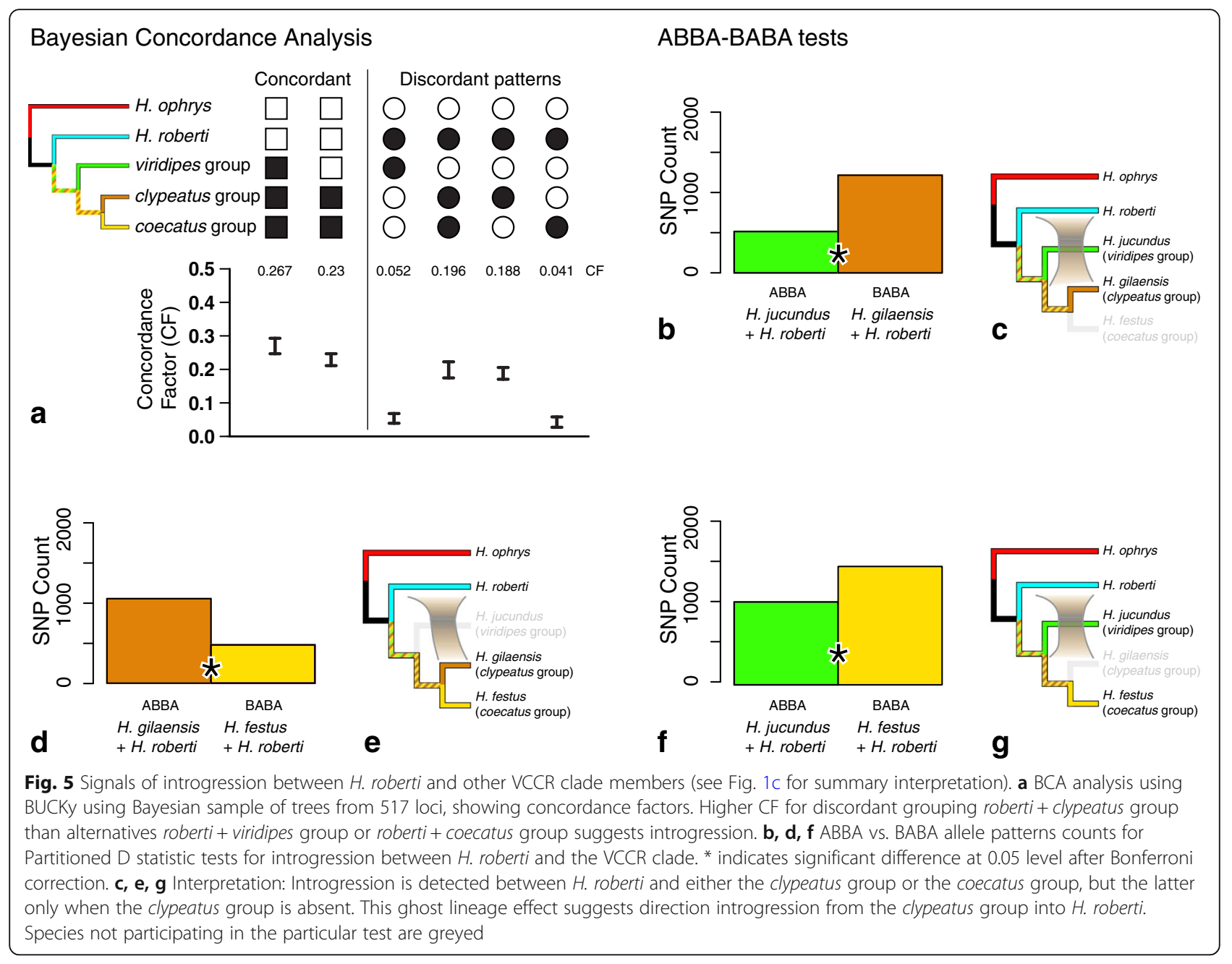

and $H$. roberti when $H$. gilaensis (clypeatus) group is excluded (Fig. 5f, $\mathrm{D}=-0.177, p<10^{-12}$; interpretation in Fig. 5g).

In $\mathrm{D}_{\mathrm{FOIL}}$ analyses of the clypeatus and coecatus groups (Fig. 6, Additional file 8: Table S3), introgression is detected between $H$. clypeatus and $H$. pyrrithrix when species 1 is the closely related $H$. gilaensis, and species 4 is either H. mexicanus (Fig. 6g, h) or H. borealis (Fig. 6i, j). The neutral rather than negative $\mathrm{D}_{\mathrm{FO}}$ and $\mathrm{D}_{\mathrm{FI}}$ values of these $\mathrm{D}_{\mathrm{FOIL}}$ signatures indicate introgression with uncertain or reciprocal direction (signatures are $\mathrm{D}_{\mathrm{FO}}=0$, $\mathrm{D}_{\mathrm{IL}}=-, \mathrm{D}_{\mathrm{FI}}=0, \mathrm{D}_{\mathrm{OL}}=-$ ).

Introgression is also detected between the common ancestor of $H$. aztecanus and $H$. clypeatus and $H$. pyrrithrix when the fourth species included is the distant coecatus group member $H$. mexicanus (Fig. 6e, f) and the less distant $H$. borealis (Fig. 6k. l) because the signature shifts from $\mathrm{D}_{\mathrm{FO}}=+, \mathrm{D}_{\mathrm{IL}}=-\mathrm{D}_{\mathrm{FI}}=0, \mathrm{D}_{\mathrm{OL}}=0$ to $\mathrm{D}_{\mathrm{FO}}=+, \mathrm{D}_{\mathrm{IL}}=-, \mathrm{D}_{\mathrm{FI}}=0, \mathrm{D}_{\mathrm{OL}}=0$. With a neutral rather than positive $\mathrm{D}_{\mathrm{FO}}$ value, the signature is no longer indicative of any single introgression event. However, it does hint at introgression between $H$. clypeatus and $H$. pyrrithrix. Support for introgression between $H$. pyrrithrix and the clypeatus group disappears when $H$. empyrus is the fourth species (Figs. 6a, c), ruling out $H$. pyrrithrix-specific introgression.

$\mathrm{D}_{\mathrm{FOIL}}$ and D-statistics results are presented in Fig. 7 and Additional file 6: Table S2, Additional file 7: Table S4, Additional file 8: Table S3 for the study of deeper introgression among the americanus group, DTB clade, and others. Several signals of introgression were detected among parts of Habronattus phylogeny that are now highly divergent.

\section{Discussion}

Using transcriptome sequence data from 1877 nuclear loci, we were able to reconstruct a phylogeny for 34 species of Habronattus with high confidence at most nodes. Far better resolved than previous results based on just two loci [5], this robust phylogenetic framework will enable more refined interpretations of character evolution, sexual selection, and hybridization. Differences in the mitochondrial and nuclear 


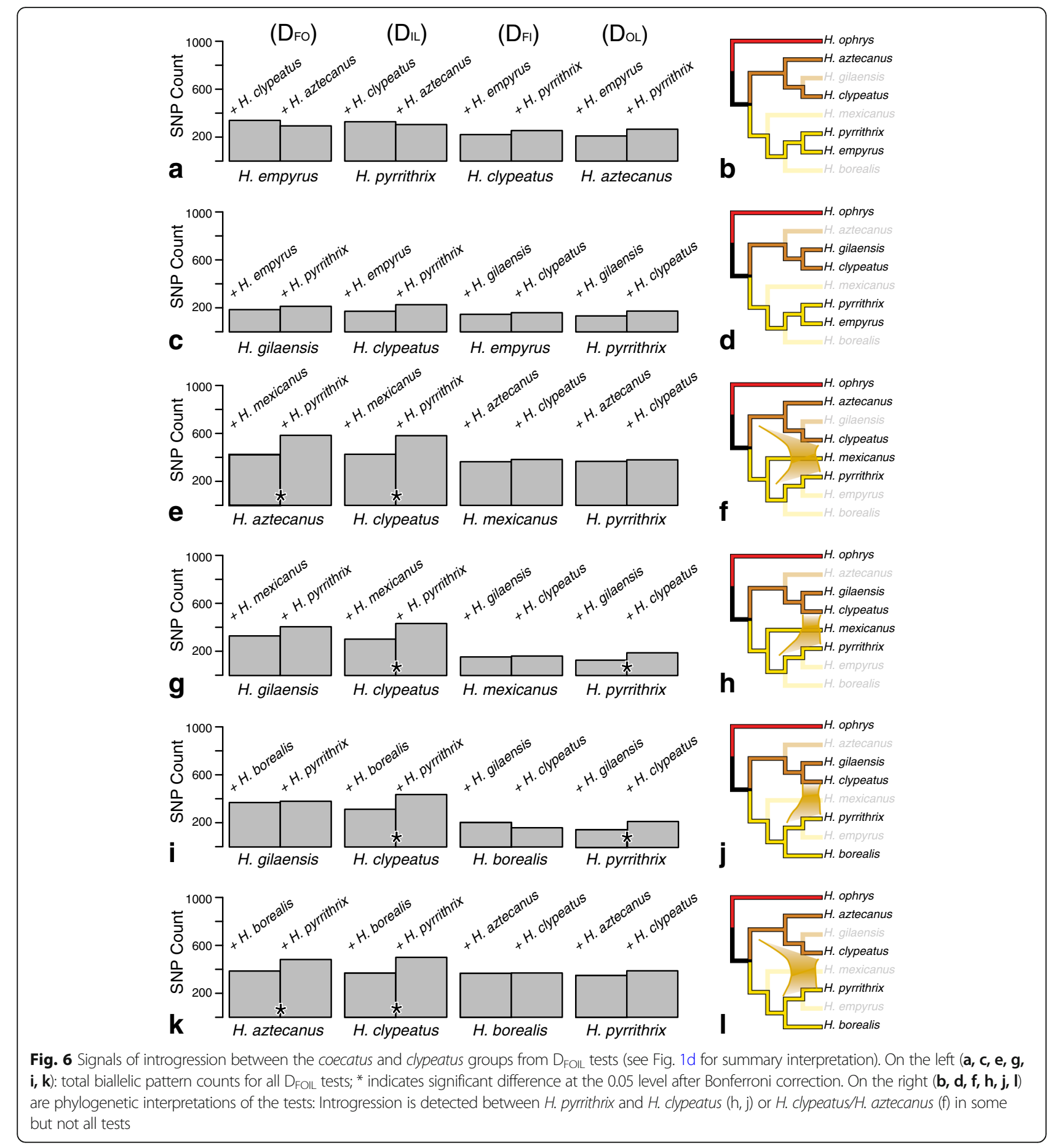

phylogenies indicate several possible instances of mitochondrial introgression, while nuclear introgression in several regions of the phylogeny is suggested by Bayesian Concordance Analysis and D-statistics and $\mathrm{D}_{\mathrm{FOIL}}$.

\section{Habronattus phylogeny}

The consistency of clade support from different partitions and methods suggests that the genetic history of
Habronattus is predominantly divergent, despite clear signs of introgression. Except for the placement of Pellenes canadensis, the relationships of $H$. cambridgei, H. oregonensis and $H$. icenoglei, and the placement of $H$. virgulatus, the phylogenetic tree shown in Fig. 1a is solidly supported as the dominant genetic history of Habronattus species.

We are doubtful of the placement of $P$. canadensis within Habronattus because of morphological support 

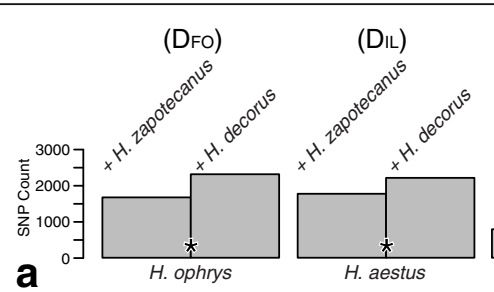

$(\mathrm{DFI})$

(DoL)
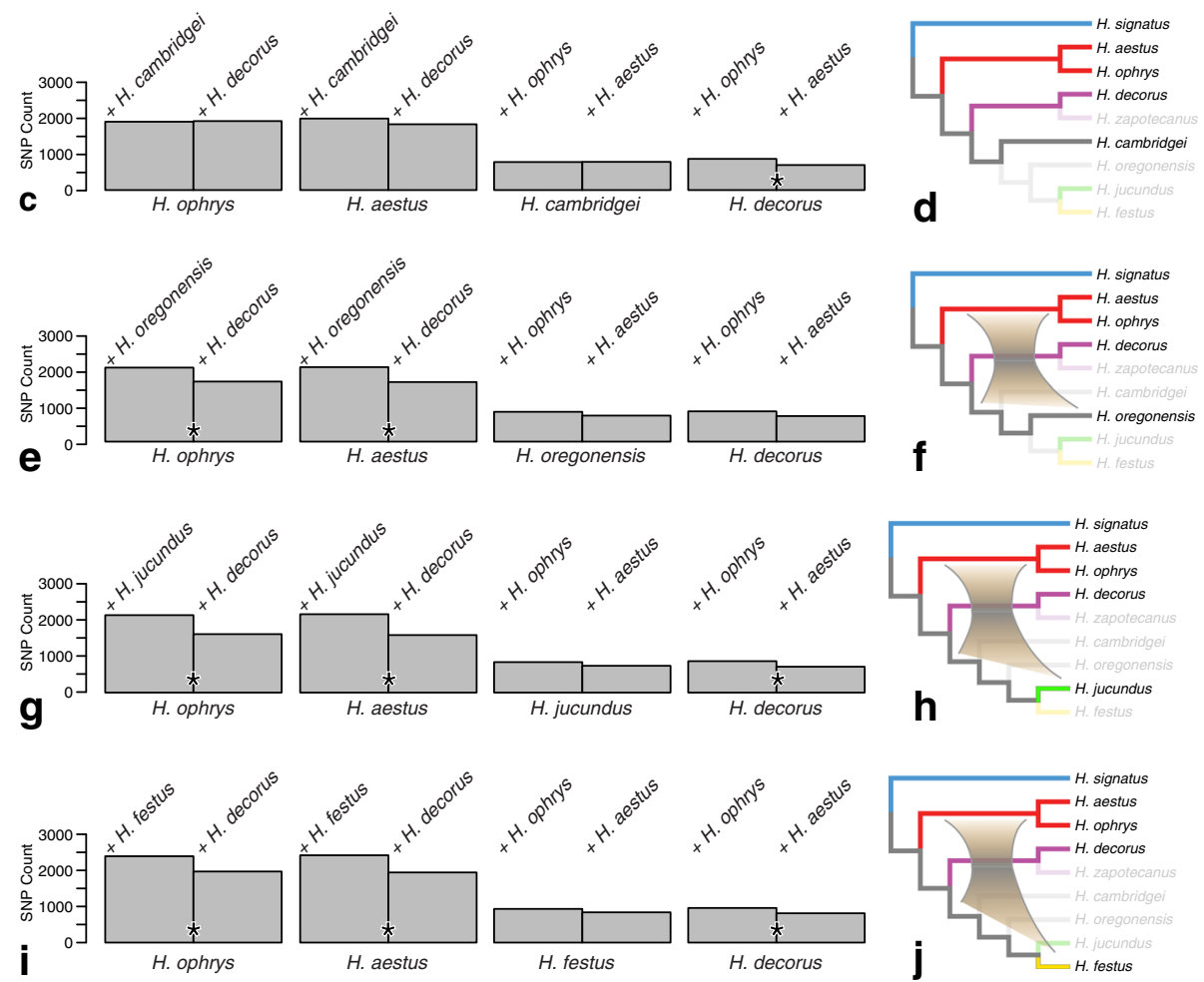

Fig. 7 Signals of introgression deeper in the phylogeny; $D_{\text {Foll }}$ tests among the americanus group (H. ophrys and H. aestus), H. decorus, $H$. zapotecanus, H. cambridgei, H. oregonensis, H. jucundus, H. festus. On the left $(\mathbf{a}, \mathbf{c}, \mathbf{e}, \mathbf{g}, \mathbf{i})$ are the total biallelic pattern counts for all $D_{\text {foll }}$ tests; ${ }^{*}$ indicates significant difference at the 0.05 level after Bonferroni correction. On the right $(\mathbf{b}, \mathbf{d}, \mathbf{f}, \mathbf{h}, \mathbf{j})$ are phylogenetic interpretations of the tests: no introgression was detected involving $H$. cambridgei (d), but introgression was detected between $H$. ophrys and $H$. decorus (a), and between the americanus group and $H$. oregonensis, H. jucundus, and H. festus or their ancestors (f, h, j)

for the monophyly of Habronattus. Against its littleornamented relatives Pellenes and Havaika, Habronattus appears well delimited by shorter first legs and a long and thin terminal apophysis (part of the male genitalia) that has a distinctive elbow on it, though the elbow is secondarily lost in the coecatus group [3,5]. Despite the apparently clear synapomorphy of the elbowed terminal apophysis, the genus does not hold together as monophyletic in many of our analyses, with Pellenes canadensis falling inside, near $H$. conjunctus or the AAT clade. We are therefore faced with three possibilities: that the elbowed terminal apophysis arose twice, that the nonelbowed terminal apophysis of Pellenes canadensis represents a reversal to the ancestral state, or that Pellenes canadensis and other members of its subgenus Pellenattus form a close sister group to Habronattus, with extremely short branches separating their early divergence, leading to difficulties in resolving the deeper relationships, especially given that the outgroup Evarcha is phylogenetically distant, in a separate subtribe (the Plexippina [37]). The choice may be resolved by having better sampling of outgroups among the Harmochirina. Because Pellenes species are also distributed in Asia [61] and Europe [62], a broader global sample of Pellenes specimens and other closely related groups (e.g., Harmochirus) should be included to better tease apart relationships at the base of the Habronattus tree and determine if the genus is monophyletic. We expect, however, that addition of outgroups would not change the wellsupported relationships within the major clade from $H$. paratus and geronimoi to the VCCR clade. The mtDNA tree (Fig. 3a), which included the additional outgroups 
Havaika, Harmochirus, Bianor, and others, is largely consistent with Fig. 1.

The reconstructed phylogeny is generally consistent with morphology [3] and the previous results from two genes [5]. The major clade whose males have fringed first legs and modified third legs (the VCCR clade) is intact as monophyletic, as are the three contained groups first recognized by morphology (viridipes, clypeatus, and coecatus groups). In this regard, the phylogeny is more concordant with morphology than that of Maddison and Hedin [5], whose analyses gave unexpected placements for $H$. jucundus (viridipes group) and split the VCCR clade. The americanus group, with distinctive genitalia and relatively long first legs, is monophyletic in the transcriptome phylogeny. The agilis, amicus and tranquillus groups hold together as the AAT clade, distinguished by compact bodies, a relatively far-rotated bulb of the male palp, and a tendency for dwelling above the ground in shrubs. As expected from the results of [5] the AAT clade is sister to the remainder of the genus, within which $H$. paratus (in the mitochondrial tree) is most basal with respect to the bulk of species, and $H$. geronimoi next.

The nuclear phylogeny provides new resolution of mid-level relationships in Habronattus. The strong support for the clade of $H$. decorus, $H$. altanus, $H$. zapotecanus and $H$. chamela indicates that their species groups (decorus, texanus, and banksi groups) form a clade, here called the DTB clade. The previously intractable $\mathrm{H}$. hallani is strongly supported as sister to $H$. luminosus and $H$. pugillis. The placement of these three species as sister to the VCCR clade is novel, as is their collective relationship with $H$. icenoglei, $H$. oregonensis, and $H$. cambridgei. For the first time there are well-supported clades within the coecatus group: H. festus, $H$. captiosus and $H$. borealis together (100\% bootstrap support) will be referred to as the Northern clade (all specimens in this clade were collected in Canada), while $H$. empyrus and $H$. pyrrithrix are sisters (100\% bootstrap support), forming the Southern clade (they are both found in the southern USA neighboring Mexico). $H$. virgulatus is sister to the Northern coecatus clade with high support (97\% bootstrap support). The relationships among the subgroups of the VCCR clade are resolved with good bootstrap support: the viridipes, clypeatus, and coecatus groups form a clade (nuclear bootstrap $=83 \%$ ), with $H$. roberti as sister to them; the clypeatus and coecatus group are sisters (100\%); and each of the viridipes, clypeatus and coecatus groups is monophyletic. $H$. jucundus groups with $H$. calcaratus rather than with the oregonensis group (a poorly supported relationship found in [5]), confirming that the viridipes group is in fact monophyletic. The internal relationships of the americanus group also have high bootstrap support.
Most of these highly supported relationships are also replicated in different nuclear subsets (see subset support summaries at the nodes in Fig. 1a), suggesting that the phylogenetic signal for most branches is robust even with less data. However, there are a few nodes with high bootstrap support that are unstable across nuclear subsets. $H$. roberti, while well supported overall as sister to the rest of the VCCR clade, also groups with the clypeatus group in some nuclear subsets. $H$. virgulatus departs from its dominant concatenated nuclear position (bootstrap support $=97 \%$ ) to group with either the Southern coecatus clade or as a basal branch of the coecatus group in some nuclear subsets. $H$. ophrys is positioned as the sister to $H$. sansoni and $H$. americanus in half of all data subsets, despite being sister to $H$. tarsalis (bootstrap support $=100 \%$ ) in the concatenated nuclear phylogeny.

Even if Habronattus has a predominantly divergent history with a clear modal gene tree, there could still be a broad scatter of discordant gene trees through incomplete lineage sorting or hybridization. Such discordance is expected from the group's youth (perhaps less than 5 million years, [17]), and is seen in our data. For instance, the VCCR clade has very low dominant CFs from the Bayesian Concordance Analysis (Fig. 3b), potentially indicating that the group is still in the early stages of divergence with widespread incomplete lineage sorting and possibly also ongoing hybridization. The indications of incomplete divergence are strongest in the coecatus group, where there are 196 secondary (conflicting) CFs that are significant (greater than 0), though most are very small and not clearly indicating ILS vs. introgression. The americanus group, on the other hand, has stronger genetic concordance (high dominant CF values) even though it is equally recently diverged ([12], fig. 4a). However, such differences in concordance could reflect differences between the groups in the density and locations of sampling, and not necessarily a difference in their evolutionary dynamics.

\section{Introgression in Habronattus}

Maddison \& Hedin [5]'s evidence for introgression was the presence in two clypeatus group specimens of mitochondrial 16SND1 more closely related to that of the coecatus group, close enough to argue against ILS as the source of discord. Our data from full mitochondrial transcriptomes indicate another case of a clypeatusgroup specimen with mitochondria falling with the coecatus group, and hint of possible introgression elsewhere in the phylogeny (in the americanus group, in the VCCR clade, and deeper in the tree).

Our tests using $\mathrm{BCA}, \mathrm{D}_{\mathrm{FOIL}}$, and D-statistics indicate that introgression extends to the nuclear genome as well. We detected nuclear introgression among closely related species, as also found by [21], ([4, 11]; pugillis group), 
and ([63]: $H$. americanus). However, our analyses also find clear signals of more distant nuclear introgression, among species groups: between $H$. roberti and the clypeatus group, between the clypeatus and coecatus groups, and apparently among even more distantly related species. We will consider the evidence for introgression separately for different regions of the phylogeny.

\section{Introgression within the americanus group}

The nuclear phylogeny, by grouping $H$. americanus with $H$. sansoni, and $H$. tarsalis with $H$. ophrys, is in accord with the informally-recognized distinction of the americanus group into the americanus subgroup and the tarsalis subgroup. The former typically have black first legs without lateral fringes and are usually found on ground covered in rocks, sticks and litter $(H$. americanus, $H$. sansoni, H. waughi (Emerton, 1926), H. bulbipes (Chamberlin \& Ivie, 1941), H. kubai (Griswold, 1979)); the latter have yellow, green or brown first legs with lateral fringes, and are typically found on grassy ground ( $H$. tarsalis, H. kawini (Griswold, 1979), $H$. mustaciata (Chamberlin \& Ivie, 1941), H. ophrys, $H$. gigas Griswold, 1987). The mitochondrial phylogeny (Fig. 2b), however, strongly supports a sister group relationship between $H$. ophrys and $H$. americanus to the exclusion of $H$. sansoni. On its own, this result could be explained by either introgression or incomplete lineage sorting. However, two introgression events in the americanus group were detected in the nuclear data.

Introgression among $H$. ophrys, $H$. americanus and $H$. sansoni is indicated by both BCA and $\mathrm{D}_{\mathrm{FOIL}}$ (Fig. 4), linking $H$. ophrys to $H$. americanus and $H$. sansoni collectively, with no sign of a preferred link to either $H$. americanus or $H$. sansoni. However, $H$. ophrys and $H$. americanus in particular are resolved as sister taxa by several nuclear data subsets (Fig. 1a) and in the mitochondrial phylogeny (Fig. 2b). Such a pattern could arise by multiple introgression events involving $H$. ophrys with either the ancestor of $H$. americanus and $H$. sansoni, or one of the two, or both separately, possibly combined with introgression between $H$. americanus and $H$. sansoni. $H$. ophrys is currently sympatric with $H$. americanus along the Pacific Coast of British Columbia, Washington and Oregon, and so may have had more opportunity to hybridize with it than with the allopatric $H$. sansoni. Introgression involving $H$. ophrys could explain the distribution of one morphological trait that is discordant with the nuclear phylogeny: tufts above the front pair of eyes, male ornaments unique in Habronattus to the americanus group, are found only in $H$. sansoni and close relatives $(H$. kubai, some $H$. americanus populations), and in $H$. ophrys.
Also found in both the BCA and D statistic tests are signals of introgression involving $H$. aestus and $H$. tarsalis (Fig. 4f). The BCA found substantial, asymmetric support linking $H$. aestus with $H$. tarsalis only compared to the conflicting clade $H$. aestus and $H$. ophrys (Fig. 4d). This pattern is also supported by ABBA-BABA tests, which detected an introgression signal between $H$. aestus and $H$. tarsalis (Fig. 4e).

Results from the BCA provide some insights into the extent of nuclear introgression. The genome-wide concordance factor of a clade is an estimate of the proportion of the genome for which the clade is true [34]. The primary $\mathrm{CF}$ and species tree put $H$. ophrys and $H$. tarsalis together, but the CF for the discordant $H$. ophrys/H. americanus/H. sansoni clade is 0.305 , indicating about $30 \%$ of the genome has those conflicting relationships. Of this 30\%, 9\% can be explained as due to ILS, given that the alternative $H$. tarsalis/H. americanus/H. sansoni clade has a CF of 0.092 . This leaves a difference of $21 \%$ that cannot be explained by ILS, suggesting that as much as $21 \%$ of the genome could have been introgressed between $H$. ophrys and $H$. americanus/H. sansoni. A similar argument suggests up to $10 \%$ introgression between $H$. aestus and $H$. tarsalis.

\section{Introgression between $\mathrm{H}$. roberti and other VCCR groups}

Ambiguity in the placement of $H$. roberti in the phylogenetic analyses hints to possible discordance. The concatenated nuclear tree and ASTRAL place $H$. roberti sister to the remainder of the VCCR clade (Fig. 1), but some partitions and SVDQuartets give other relationships, e.g. as sister to the clypeatus group, sister to the clypeatus plus coecatus groups, sister to the viridipes group, or sister to the coecatus group. The primary concordance tree from BCA places $H$. roberti as sister to the remainder of the VCCR clade, but with a weak concordance factor ( $\mathrm{CF}=0.267$; Fig. 5a).

Both BCA and D statistics suggest that the ambiguity in the placement of $H$. roberti is not due solely to short branches or incomplete lineage sorting, but involves a strong component of discordance from introgression. Discordant patterns show a strong asymmetry toward $H$. roberti plus the clypeatus group (BCA, Fig. 5a; ABBABABA, Figs. 5b-g) rather than the alternatives of $H$. roberti plus the viridipes group or the coecatus group. When the clypeatus group is excluded from tests, a signal for introgression is seen between $H$. roberti and the coecatus group (Figs. $5 \mathrm{f}$ and g), but this is likely as ghost lineage effect $([32,63])$, as this signal shifts to the clypeatus group when included (Figs. $5 \mathrm{~d}$ and e). This ghost lineage effect suggests a direction of the introgression: from the clypeatus group into $H$. roberti [59]. By Figs. 5d and e, the strong signal is between $H$. roberti and the clypeatus group. If $H$. roberti were the donor species 
instead, into the clypeatus group, then we would expect to see sharing of alleles between just those two, failing to predict the ghost effect of sharing between $H$. roberti and the coecatus group (Figs. $5 \mathrm{f}$ and g). Following a similar argument to that given for the americanus group, the excess CF difference of 0.14 for the discordant clade $H$. roberti plus the clypeatus group compared to contrasting discordant patterns (CF 0.188 compared to 0.04-0.05) could suggest that $14 \%$ of the genome of $H$. roberti is introgressed from the clypeatus group.

The muddled nature of genetic relationships of $H$. roberti is echoed in its phenotype. The species was considered part of the viridipes group by Maddison and Hedin [5] based on its sharing the latter's synapomorphy of a raised ridge of setae between the male's posterior eyes [35]. However, $H$. roberti has a clearly visible checkered pattern of pigment in the male anterior median eyes, otherwise known only from the clypeatus group [35]. It also has a dark medial ventral abdominal stripe, as in the clypeatus group. Males from some populations of $H$. roberti have red-purple bumps on their third leg's patella [35], a trait found otherwise only in clypeatus group species $H$. cf. arcalorus "CHIH", H. formosus (Banks, 1906), and $H$. velivolus Griswold, 1987 (a species sympatric with H. roberti). If $H$. roberti is sister to the VCCR clade as per the nuclear phylogeny, those traits in which it resembles the viridipes group could be ancestral to the VCCR clade, with its clypeatus-group traits acquired by introgression.

\section{Introgression between the coecatus and clypeatus group}

Our finding of a third case of mitochondrial sequences in the clypeatus group falling in the coecatus group (Fig. 3a) adds to the previous results of Maddison and Hedin [5]. Our $H$. clypeatus specimen has a mitochondrial genome nestled well within the coecatus group, strongly supported by the whole mitochondrial transcriptome (Fig. 2b). Maddison and Hedin [5] found specimens of $H$. velivolus and $H$. cf. arcalorus "CHIH" with 16SND1 sequences closely resembling those of the coecatus group. In each case, these species are polymorphic, with specimens from the same or other locations showing typical clypeatus-group mitochondrial genes. ILS is formally a possible explanation, requiring that the mitochondrial lineage dominant in the clypeatus group went extinct or unsampled in the coecatus group. However, if ILS were the cause of discord, the mitochondrial lineages shared between unusual clypeatus group specimens and the coecatus group would have to extend deeper than the common ancestor of the 35 described species in the clade containing the clypeatus and coecatus groups. However, the sequence divergences are small for example, the divergence between $H$. velivolus HA659 (clypeatus group) and $H$. pyrrithrix HA010 (coecatus group) is about the same as that among the three $H$. virgulatus specimens from Arizona. If divergence between HA659 and HA010 mitochondria was prior to the split of the two species groups, this would suggest that either the three $H$. virgulatus mitochondria also extend that deep and just by luck managed to sort themselves into three specimens of the same morphospecies, or the rate of sequence divergence in $H$. virgulatus has drastically sped up. Recent mitochondrial introgression is a simpler explanation.

A signal for nuclear introgression between the coecatus and clypeatus groups, possibly many events, is found via $\mathrm{D}_{\mathrm{FO}}$ tests. Introgression is detected between $H$. pyrrithrix and $H$. clypeatus (Figs. $6 \mathrm{~g}-\mathrm{j}$ ), and between the common ancestor of $H$. aztecanus and $H$. clypeatus and H. pyrrithrix (Figs. 6e and f). However, these signals are lost whenever $H$. empyrus, the sister taxon of $H$. pyrrithrix, is included in the test, ruling out $H$. pyrrithrix-specific introgression. The signal is also partially lost, producing $\mathrm{D}_{\mathrm{FOIL}}$ signatures inconsistent with a single introgression event, when $H$. mexicanus (Fig. 6e) is replaced by $H$. borealis (Fig. 6 and k) as the coecatus species used for comparison. The complex pattern of $\mathrm{D}_{\mathrm{FOIL}}$ signatures that vary depending on the species included for comparison could be explained by multiple introgression events. It does not indicate a clear direction (coecatus group into clypeatus group or vice versa). However, the lack of an introgression signal in Figs. 6a-d helps pinpoint the origin of the introgression signal in the coecatus group to an unidentified ghost taxon from the Southern clade that is closely related to $H$. pyrrithrix.

Despite the clear signal of introgression from $D_{\mathrm{FOIL}}$, the BCA does not show any concordance factors of greater than 0.05 intermixing the clypeatus and coecatus groups. Although there are 35 significant (not overlapping 0) CFs that link H. clypeatus with coecatus group species, these are so small (averaging 0.01 ) that they cannot be attributed to introgression - low CF values are likely to be overestimated [54], and are just as likely to be a result of ILS or noisy gene trees [33].

The mitochondrial and nuclear results could be an indication of frequent introgression between the clypeatus group (containing 10 species) and coecatus group (24 species). This is unexpected, as these clades differ substantially and consistently in morphology and courtship behaviour $[5,6,64]$. The male courtship display is highly complex in both groups, but differs in morphological ornaments, behaviours, and acoustic signals $[6,64]$. Genital morphology is also quite different in males and females of the two groups [3]. Species of the coecatus group lack an elbow on the male palp's terminal apophysis, present in all clypeatus group species [3]. The clypeatus group has a male tibial apophysis that is thinner and hook-like; the coecatus group thicker and more triangular. The possibility of hybridization despite these 
substantial differences related to mating is worth noting. Because of a predicted evolutionary lag between male sexually selected traits and female preferences [65], species-specific differences in male mating traits do not always result in reproductive isolation [66]. However, given the considerable phylogenetic distance and differences between clypeatus and coecatus groups, isolation would have been expected.

\section{Introgression signal as artifact?}

Our inference of nuclear introgression is based on a dataset sorted into proposed orthologs and assumed to be free of contamination. Were some of our "loci" a blend of different paralogs, some resulting gene trees may appear (falsely) to reveal introgression. However, these "loci" discordant with the primary species tree would not be expected to have a consistent direction of discord, instead adding non-directional noise, unless we suppose an elaborate scenario (e.g. chromosome duplication in a shared ancestor, with the alternatives marked and later deleted wholesale in different descendants). There is no cytogenetic reason to suspect large-scale duplications: except for H. banksi (Peckham \& Peckham, 1901) and H. zapotecanus, all Habronattus have the same number of chromosome arms and approximately the same size of chromosomes (71 species studied in Maddison \& Leduc-Robert [12], including most reported here). While paralogs might have survived our filters, it is unlikely that they generated our signals of introgression.

A more serious concern would be cross-sample contamination [67], which could mimic introgression closely. Ballenghien et al. [67] noted that contamination was most likely between samples sharing a batch at a sequencing facility. Our samples were run in five batches separated by many months or in different facilities: (1) H. festus and ophrys; (2) H. aztecanus, cambridgei, captiosus, chamela, hirsutus, mexicanus, paratus, roberti, and zapotecanus; (3) H. signatus and ustulatus; (4) H. gilaensis; and (5) all other taxa. Of our four primary conclusions of introgression (Figs. 1 b, c and d), one can be easily defended: $H$. ophrys was in a different sequencing batch from $H$. americanus and $H$. sansoni. The other tests of introgression could have been compromised by within-batch contamination. For example, $H$. roberti shared a sequencing batch with $H$. aztecanus, a clypeatus group member sympatric with $H$. roberti, and thus a possible source of the patterns of Fig. 5 through either contamination or introgression. However, although contamination should be acknowledged as a possibility, it is unlikely to be the source of introgression signals in $H$. roberti. Most critically, contamination from $H$. aztecanus would predict a pattern of biased discord similar in nuclear and mitochondrial genomes, while introgression would predict a different pattern in the mtDNA, with a single clear tree and no biased discord among sites. The latter is what we see. The nuclear ABBA-BABA test of Figs. $5 \mathrm{~d}$ for $H$. festus - gilaensis - roberti - ophrys shows a strong bias of 1051 for ABBA versus 476 for BABA (Additional file 7:Table S4), but the corresponding test on mtDNA (reordered H. festus - roberti - gilaensis ophrys to match the inferred mitochondrial tree) shows no bias, with 89 sites ABBA and 88 BABA (and 215 BBAA). There is no sign of a minority signal in the mtDNA, against the predictions of contamination. In addition, our protocol would have scored as ambiguous, and thus excluded from D statistics tests, any nucleotide unless it reached more than $70 \%$ prevalence among reads at a site in our protocol. Ballenghein et al.'s [67] data suggest it rare for a contaminant to achieve such high prevalence: just 6 of their $446 \operatorname{cox} 1$ samples exceed a 7:3 ratio of unexpected:expected reads (their fig. $2 \mathrm{~b}$ ). A frequency of 6/446 is not high to yield the biases we observed (Additional file 7: Table S4). Finally, $H$. roberti is not an outlier in percentage of sites with ambiguous calls. Similar arguments can be given for the other conclusions of introgression in Fig. 1, and thus contamination is not a likely alternative explanation.

\section{Signals of broader introgression}

Ancient introgression deeper in Habronattus phylogeny is suggested by both the mitochondrial phylogeny and D statistics. Mitochondrial introgression between the americanus group and the DTB clade could explain why these groups form a clade in the mitochondrial transcriptome phylogeny (Fig. 2b) but are separate and distant clades in the nuclear phylogeny (Fig. 2a). When we explored this further in the nuclear data with Dstatistics, we found introgression signals shared not only between the americanus group and $H$. decorus, but also with many more distant species (Fig. 7). These results are difficult to interpret because the phylogenetic distance obscures the donor and recipient lineages, and multiple introgression events could create conflicting signals.

\section{Potential drivers of hybridization}

Our results indicate a clear genomic signature of introgression in Habronattus among species groups with strong phenotypic differences in courtship and genitalia, differences which might have been expected to provide reproductive isolation. We found introgression not only between the clypeatus and coecatus groups (as in [5]), but also between $H$. roberti and the clypeatus group, and possibly other more distant species.

Evidence for directional introgression involving the coecatus group may hint at what processes have driven hybridization despite divergent morphology and behaviour. Courtship of the coecatus group is strikingly complex [6], more complex than any other known in 
Habronattus. Mitochondrial data suggest introgression from the coecatus group into the clypeatus group (Figs. 2b, 3a), but nuclear data show hints of multiple introgressions with no clear directionality (Fig. 6). Directionality of mitochondrial introgression but not nuclear introgression could be the result of sex-biased hybridization, driven by a difference in female discrimination [68] causing coecatus females to sometimes hybridize with clypeatus group males but not the other way around. In some Habronattus (outside of the coecatus and clypeatus groups), females have been found to prefer foreign males from divergent populations (H. pugillis; [7]). Such xenophilia could be a consequence of an arms race between the sexes [27] involving sensory exploitation: males would evolve novel exploitative signals; females evolve resistance to their own males, but not to new signals evolved in foreign lineages to which the females have not been exposed, but which share common sensory biases [6, 7]. If females of a species group (e.g. the coecatus group) are particularly susceptible to novel signals, then this could lead both to higher courtship complexity in that group, and to their females' tendency to donate mitochondria to distant species. Thus, the tendency to hybridize might correlate positively with more complex courtship behaviour. However, other factors could promote asymmetric introgression. Hedin and Lowder [21] suggested asymmetrical overlap in body size distributions could explain the directional introgression they found in the amicus group of Habronattus. Demographic characteristics of hybridizing species [23], such as differences in population size [69] and dispersal behaviours [70], could also cause asymmetric introgression.

\section{Evolutionary consequences of introgression}

Introgression in Habronattus may have been frequent enough to result in detectable nuclear admixture, but infrequent enough so as not to be a homogenizing force reducing genetic and morphological diversity [24]. For instance, Blackburn and Maddison [71] found evidence for gene flow among parapatric subpopulations of $H$. americanus, and yet they showed consistent courtship display differences. Both substantial introgression and rapid diversification are found in the species-rich americanus group (12 species) and the VCCR clade (42 species), both of which have remarkable diversities of male ornaments. In the VCCR group, as much as $14 \%$ of derived alleles are shared between distantly related clypeatus/coecatus groups and $H$. roberti due to introgression, while closely related americanus group species $H$. ophrys and $H$. americanus $/ H$. sansoni share up to $21 \%$ of derived alleles as a result of introgression.

It is unclear whether introgression has played a creative evolutionary role in Habronattus, either by promoting diversification or by influencing the phylogenetic distribution of traits. Distant introgression, which we detected in several clades, is more likely to have adaptive effects on lineages because novel and potentially adaptive genetic combinations are more likely to form as a result of introgression when there is more time to accumulate genetic differences [72, 73]. Introgression could also create adaptive potential by increasing the standing variation of hybridizing lineages, which could facilitate subsequent diversification [73]. There are an increasing number of documented cases of adaptive introgression [74-76] and introgression-facilitated diversification in animals [77, 78]. Given the strength of sexual selection in Habronattus [1, 2, 11], loci implicated in sexually selected traits could be under strong selection if they were exchanged between hybridizing species. We have suggested two courtship traits in Habronattus whose phylogenetic distributions could be explained by introgression: the red-purple bumps on the third legs of males of $H$. roberti and members of the clypeatus group, and the distinctive "eyebrows" of $H$. ophrys and $H$. sansoni. A denser phylogenetic sample of Habronattus species will be needed to better resolve whether such similarities discordant with the species tree are best explained by distant introgression.

\section{Conclusions}

We produced a highly resolved phylogeny of Habronattus and determined the contributions of hybridization and incomplete lineage sorting to genetic discordance in the group. We found that hybridization has been common in Habronattus phylogeny, and has resulted in considerable nuclear introgression in some instances (e.g., the americanus group, $H$. roberti) and lesser nuclear introgression accompanied by strong mitochondrial introgression in others (i.e., among the coecatus and clypeatus groups). However, we were unable to detect specific lineages and direction of introgression in many cases, for which a denser sample of species will be important. Widespread introgression between both distant and closely related species indicates that only partial reproductive isolation has evolved across much of the Habronattus phylogeny. Introgression has occurred between Habronattus species groups with divergent male ornaments and courtship behaviours. Further research should focus on determining the extent of introgression's contribution to adaptation and diversification. In particular, widespread introgression in the highly diverse VCCR clade could be indicative of a correlation between introgression and diversification.

\section{Additional files}

Additional file 1: Table S1. Summary of RNA-sequencing and transcriptome assemblies for all species (except DNA sequencing of $H$. paratus). (PDF 616 kb) 
Additional file 2: NEXUS files of aligned matrices (five text files, NEXUS format, totaling $131 \mathrm{mb}$, compressed to a single zip file of $12 \mathrm{mb}$ ) (ZIP $15390 \mathrm{~kb})$

Additional file 3: NEXUS file of the phylogenetic trees from various analyses (text, NEXUS format $250 \mathrm{~kb}$ ) (TXT $244 \mathrm{~kb}$ )

Additional file 4: Concordance file for americanus group. (TXT $74 \mathrm{~kb}$ )

Additional file 5: Concordance file for VCCR clade (text $4.3 \mathrm{mb}$ ) (TXT $4182 \mathrm{~kb}$ )

Additional file 6: Table S2. Counts of alleles shared among Habronattus species used for DFoll tests. (PDF $405 \mathrm{~kb}$ )

Additional file 7: Table S4.. Patterson's D statistic results and counts of allele patterns. (PDF $455 \mathrm{~kb}$ )

Additional file 8: Table S3. $D_{\mathrm{FOIL}}$ results. (PDF $476 \mathrm{~kb}$ )

\section{Abbreviations}

AAT: The clade of species including the agilis, amicus, tranquillus groups.; BCA: Bayesian Concordance Analysis.; bp: Base pair (1 nucleotide).; CF: Concordance factor.; Cl: Credibility interval.; DTB: The clade of species including the decorus, texanus, and banksi groups.; ILS: Incomplete lineage sorting.; kb: Kilobase (1 thousand nucleotides); Mb: Megabase (1 million nucleotides).; ML: Maximum likelihood.; MS: "Missing Species", a subset of the data.; NL: "Noncoding Loci", a subset of the data.; VCCR: the clade of species including the viridipes, coecatus, clypeatus, and roberti groups.

\section{Acknowledgments}

We thank Heather Proctor, Sam Evans, Abraham Meza López, and Tila María Perez for help collecting specimens for this project in 2013 and 2014. Marshal Hedin and Megan Porter graciously contributed sequencing data for three of the species. Allyson MisCampbell and Carol Ritland from the Genomic Data Centre at UBC, and Jeff Richards and his students, generously assisted with laboratory resources and advice. Anastasia Kuzmin facilitated the sequencing process and gave valuable advice. Saemundur Sveinsson gave helpful bioinformatics assistance. Westgrid (CanadaComputes) supplied access to their computer clusters. Marshal Hedin gave helpful comments on an earlier version of the manuscript. We thank also Sally Otto, Loren Rieseberg, Darren Irwin, Edy Piascik, Junxia Zhang, Gwylim Blackburn, Sam Evans, Hervé Philippe, and three anonymous reviewers for their helpful feedback and ideas.

\section{Funding}

This work was supported by an NSERC Discovery grant to WPM. The funders had no role in study design, data collection and analysis, decision to publish, or preparation of the manuscript.

\section{Availability of data and materials}

The sequencing reads of transcriptomes are archived in the Sequence Read Archive [79]. Accession numbers are indicated in Additional file 1: Table S1. NEXUS files containing the aligned matrices of the 1877 loci in the primary dataset, and files detailing the results of analyses supporting the conclusions of this article are included within its Additional files. The NEXUS files are also available in the Dryad repository [38].

\section{Authors' contributions}

WPM and GLR co-designed the study. WPM led the collecting of specimens, with contributions from GLR and collaborators (listed in Acknowledgments). GLR performed the lab work and analyses of data, including writing of scripts for processing data. WPM wrote custom modules in Mesquite for data processing. GLR wrote the first draft of the manuscript, which was subsequently co-written by GLR and WPM. Both authors have read and approved the manuscript.

\section{Ethics approval and consent to participate}

Not applicable.

\section{Consent for publication}

Not applicable.

\section{Competing interests}

The authors declare that they have no competing interests.

\section{Publisher's Note}

Springer Nature remains neutral with regard to jurisdictional claims in published maps and institutional affiliations.

Received: 5 April 2017 Accepted: 15 February 2018

Published online: 22 February 2018

\section{References}

1. Peckham GW, Peckham EG. Observations on sexual selection in spiders of the family Attidae. Occas Pap Nat Hist Soc Wisconsin. 1889;1:117-51.

2. Peckham GW, Peckham EG. Additional observations on sexual selection in spiders of the family Attidae: with some remarks on Mr. Wallace's theory of sexual ornamentation. Occas. Pap. Nat. Hist. Soc. Wisconsin. 1.3. National History Society of Wisconsin. 1890;1:3-60.

3. Griswold CE. A revision of the jumping spider genus Habronattus FOPCambridge (Araneae; Salticidae), with phenetic and cladistic analyses. Univ Calif Publ Entomol Univ of California Press. 1987;107:1-344

4. Maddison WP, McMahon MM. Divergence and reticulation among montane populations of a jumping spider (Habronattus pugillis Griswold). Syst Biol. 2000;49:400-21.

5. Maddison WP, Hedin MC. Phylogeny of Habronattus jumping spiders (Araneae: Salticidae), with consideration of genitalic and courtship evolution. Syst Entomol. 2003;28:1-22

6. Elias DO, Maddison WP, Peckmezian C, Girard MB, Mason AC. Orchestrating the score: complex multimodal courtship in the Habronattus coecatus group of Habronattus jumping spiders (Araneae: Salticidae). Biol J Linn Soc. 2012; 105:522-47.

7. Hebets EA, Maddison WP. Xenophilic mating preferences among populations of the jumping spider Habronattus pugillis Griswold. Behav Ecol. 2005;16:981-8.

8. Scheidemantel DD. Behavioral and natural history studies of the jumping spider Habronattus oregonensis and inquiry based secondary laboratory lesson development stemming from university research, MSc thesis. Tucson: The University of Arizona; 1997.

9. Elias DO. Female preference for complex/novel signals in a spider. Behav Ecol. 2006;17:765-71.

10. Blackburn GS, Maddison WP. Stark sexual display divergence among jumping spider populations in the face of gene flow. Mol Ecol. 2014;23: 5208-23.

11. Masta SE, Maddison WP. Sexual selection driving diversification in jumping spiders. Proc Natl Acad Sci U S A. 2002:99:4442-7.

12. Maddison WP, Leduc-Robert G. Multiple origins of sex chromosome fusions correlated with chiasma localization in Habronattus jumping spiders (Araneae: Salticidae). Evolution. 2013;67:2258-72.

13. Maddison WP. XXXY sex chromosomes in males of the jumping spider genus Pellenes (Araneae: Salticidae). Chromosoma. 1982;85:23-37.

14. Zurek DB, Cronin TW, Taylor LA, Byrne K, Sullivan MLG, Morehouse NI. Spectral filtering enables trichromatic vision in colorful jumping spiders. Curr Biol. 2015;25:R403-4.

15. Taylor LA. Color and communication in Habronattus jumping spiders: tests of sexual and ecological selection. PhD dissertation. Tempe: Arizona State University; 2012.

16. Taylor LA, Amin Z, Maier EB, Byrne KJ, Morehouse NI. Flexible color learning in an invertebrate predator: Habronattus jumping spiders can learn to prefer or avoid red during foraging. Behav Ecol. 2016;27:520-9.

17. Bodner MR, Maddison WP. The biogeography and age of salticid spider radiations (Araneae: Salticidae). Mol Phylogenet Evol. 2012;65:213-40.

18. Degnan J, Rosenberg N. Gene tree discordance, phylogenetic inference and the multispecies coalescent. Trends Ecol Evol. 2009;24:332-40.

19. Grant PR, Grant BR, Petren K. Hybridization in the recent past. Am Nat. 2005; 166:56-67.

20. Donnelly MJ, Pinto J, Girod R, Besansky NJ, Lehmann T. Revisiting the role of introgression vs shared ancestral polymorphisms as key processes shaping genetic diversity in the recently separated sibling species of the Anopheles gambiae Complex. Heredity (Edinb). 2004;92:61-8.

21. Hedin MC, Lowder MC. Phylogeography of the Habronattus amicus species complex (Araneae: Salticidae) of western North America, with evidence for localized asymmetrical mitochondrial. Zootaxa. 2009;2307:39-60. 
22. Pease J, Hahn M. Detection and polarization of introgression in a five-taxon phylogeny. Syst Biol. 2015;64:651-62.

23. Toews DPL, Brelsford A. The biogeography of mitochondrial and nuclear discordance in animals. Mol Ecol. 2012;21:3907-30.

24. Slatkin M. Gene flow in natural populations. Annu Rev Ecol Syst. 1985;16: 393-430.

25. Twyford AD, Ennos RA. Next-generation hybridization and introgression. Heredity (Edinb). 2012;108:179-89.

26. Rieseberg L, Raymond O, Rosenthal D, Lai Z. Major ecological transitions in wild sunflowers facilitated by hybridization. Science. 2003;301:1211-6.

27. Holland B, Rice W. Perspective: chase-away sexual selection: antagonistic seduction versus resistance. Evolution. 1998;52:1-7.

28. Ryan MJ, Keddy-Hector A. Directional patterns of female mate choice and the role of sensory biases. Am Nat. 1992;139:54-35.

29. Schwenk K, Brede N, Streit B. Introduction. Extent, processes and evolutionary impact of interspecific hybridization in animals. Philos. Trans. R. Soc. Lond. B. Biol. Sci. 2008:363:2805-11.

30. Yu Y, Than C, Degnan JH, Nakhleh L. Coalescent histories on phylogenetic networks and detection of hybridization despite incomplete lineage sorting. Syst Biol. 2011;60:138-49.

31. Kronforst M, Young L, Blume L, Gilbert L. Multilocus analyses of admixture and introgression among hybridizing Heliconius butterflies. Evolution. 2006; 60:1254-68.

32. Durand EY, Patterson N, Reich D, Slatkin M. Testing for ancient admixture between closely related populations. Mol Biol Evol. 2011;28:2239-52.

33. Baum DA. Concordance trees, concordance factors, and the exploration of reticulate genealogy. Taxon. 2007;56:417-26.

34. Ané C, Larget B, Baum D, Smith SD, Rokas A. Bayesian estimation of concordance among gene trees. Mol Biol Evol. 2007;24:412-26.

35. Maddison WP. New species of Habronattus and Pellenes jumping spiders (Araneae: Salticidae: Harmochirina). ZooKeys. 2017;646:45-72.

36. Maddison WP, Maddison DR. Two new jumping spider species of the Habronattus clypeatus group (Araneae, Salticidae, Harmochirina). ZooKeys. 2016;625:1-10.

37. Maddison WP. A phylogenetic classification of jumping spiders (Araneae: Salticidae). J Arachnol. 2015;43:231-92.

38. Leduc-Robert G, Maddison WP. Aligned data matrices and resulting trees for Habronattus transcriptome phylogeny. 2017. https://doi.org/10.5061/dryad. $5 \mathrm{~kg} 33$.

39. Andrews S. FastQC: a quality control tool for high throughput sequence data. 2010. http://www.bioinformatics.babraham.ac.uk/projects/fastqc. Accessed 8 July 2015.

40. Aronesty E. ea-utils: command-line tools for processing biological sequencing data. 2011. https://expressionanalysis.github.io/ea-utils/. Accessed 20 Feb 2018

41. Schmieder R, Edwards R. Quality control and preprocessing of metagenomic datasets. Bioinformatics. 2011;27:863-4.

42. Haas BJ, Papanicolaou A, Yassour M, Grabherr M, Blood PD, Bowden J, et al. De novo transcript sequence reconstruction from RNA-seq using the trinity platform for reference generation and analysis. Nat Protoc. 2013;8:1494-512.

43. Li B, Dewey C. RSEM: Accurate transcript quantification from RNA-Seq data with or without a reference genome. BMC Bioinformatics. 2011;12:323.

44. Fu L, Niu B, Zhu Z, Wu S, Li W. CD-HIT: accelerated for clustering the nextgeneration sequencing data. Bioinformatics. 2012;28:3150-2.

45. Masta SE, Boore JL. The complete mitochondrial genome sequence of the spider Habronattus oregonensis reveals rearranged and extremely truncated tRNAs. Mol Biol Evol. 2004;21:893-902

46. Katoh $\mathrm{K}$, Standley D. MAFFT multiple sequence alignment software version 7 : improvements in performance and usability. Mol Biol Evol. 2013;30:3059-66.

47. Maddison WP, Maddison DR. Mesquite: a modular system for evolutionary analysis. Version 3.02. 2011. Accessed 7 Jan 2015.

48. Stamatakis A. RAxML-VI-HPC: maximum likelihood-based phylogenetic analyses with thousands of taxa and mixed models. Bioinformatics. 2006;22:2688-90.

49. Lanfear R, Calcott B, Ho S, Guindon S. PartitionFinder: combined selection of partitioning schemes and substitution models for phylogenetic analyses. Mol Biol Evol. 2012;29:1695-701.

50. Mirarab S, Reaz R, Bayzid MS, Zimmermann T, Swenson MS, Warnow T. ASTRAL: genome-scale coalescent-based species tree estimation. Bioinformatics. 2014;30:1541-8.
51. Chifman J, Kubatko L. Identifiability of the unrooted species tree topology under the coalescent model with time-reversible substitution processes, site-specific rate variation, and invariable sites. J Theor Biol. 2015;374:35-47.

52. Mirarab S, Warnow T. ASTRAL-Il: coalescent-based species tree estimation with many hundreds of taxa and thousands of genes. Bioinformatics. 2015;31:i44-52.

53. Swofford DL. PAUP*. Phylogenetic analysis using parsimony (* and other methods). Version 4. Sunderland, MA: Sinauer Associates; 2002.

54. Ané C. Reconstructing concordance trees and testing the coalescent model from genome-wide data sets. In: Knowles LL, Kubatko LS, editors. Estimating species trees: practical and theoretical aspects. Hoboken, NJ: Wiley-Blackwell; 2010. p. 35-52.

55. Ronquist F, Huelsenbeck J. MrBayes 3: Bayesian phylogenetic inference under mixed models. Bioinformatics. 2003;19:1572-4.

56. Ronquist F, Huelsenbeck J, Teslenko M. MrBayes 3.2 Manual. 2011. http:// mrbayes.sourceforge.net/mb3.2_manual.pdf. Accessed 30 Sept 2015.

57. Larget B, Kotha S, Dewey C, Ané C. BUCKy: gene tree/species tree reconciliation with Bayesian concordance analysis. Bioinformatics. 2010;26: 2910-1.

58. Durand E, Patterson N, Reich D, Slatkin M. Testing for ancient admixture between closely related populations. Mol Biol Evol. 2011;28:2239-52.

59. Eaton D, Hipp A, González-Rodríguez A, Cavender-Bares J. Historical introgression among the American live oaks and the comparative nature of tests for introgression. Evolution. 2015;69:2587-601.

60. Miller JR, Koren S, Sutton G. Assembly algorithms for next-generation sequencing data. Genomics. 2010;95:315-27.

61. Logunov DV, Marusik YM, Rakov SY. A review of the genus Pellenes in the fauna of Central Asia and the Caucasus (Araneae, Salticidae). J Nat Hist. 1999;33:89-148.

62. Metzner H. Die Springspinnen (Araneae, Salticidae) Griechenlands. Andrias. 1999;14:1-279.

63. Eaton DAR, Ree RH. Inferring phylogeny and introgression using RADseq data: an example from flowering plants (Pedicularis: Orobanchaceae). Syst Biol. 2013;62:689-706.

64. Elias DO, Mason AC, Maddison WP, Hoy RR. Seismic signals in a courting male jumping spider (Araneae: Salticidae). J Exp Biol. 2003;206:4029-39.

65. Schluter D, Price T. Honesty, perception and population divergence in sexually selected traits. Proc R Soc London B Biol Sci. 1993;253:117-22.

66. Panhuis TM, Butlin R, Zuk M, Tregenza T. Sexual selection and speciation. Trends Ecol Evol. 2001;16:364-71.

67. Ballenghien M, Faivre N, Galtier N. Patterns of cross-contamination in a multispecies population genomic project: detection, quantification, impact, and solutions. BMC Biol. 2017;15:25.

68. Avise J. Cytonuclear genetic signatures of hybridization phenomena: rationale, utility, and empirical examples from fishes and other aquatic animals. Rev Fish Biol Fish. 2000;10:253-63.

69. Lepais O, Petit RJ, Guichoux E, Lavabre JE, Alberto F, Kremer A, Gerber S. Species relative abundance and direction of introgression in oaks. Mol Ecol. 2009;18:2228-42.

70. Funk DJ, Omland KE. Species-level paraphyly and polyphyly: frequency, causes, and consequences, with insights from animal mitochondrial DNA. Annu Rev Ecol Evol Syst. 2003;34:397-423.

71. Maddison WP, Blackburn GS. Insights to the mating strategies of Habronattus americanus jumping spiders from natural behaviour and staged interactions in the wild. Behaviour. 2015;152:1169-86.

72. Stelkens R, Seehausen O. Genetic distance between species predicts novel trait expression in their hybrids. Evolution. 2009;63:884-97.

73. Seehausen $\mathrm{O}$. Conditions when hybridization might predispose populations for adaptive radiation. J Evol Biol. 2013;26:279-81.

74. Huerta-Sánchez E, Jin X, Asan, Bianba Z, Peter BM, Vinckenbosch N, et al. Altitude adaptation in Tibetans caused by introgression of Denisovan-like DNA. Nature. 2014:512:194-7.

75. Norris LC, Main BJ, Lee Y, Collier TC, Fofana A, Cornel AJ, Lanzaro GC. Adaptive introgression in an African malaria mosquito coincident with the increased usage of insecticide-treated bed nets. Proc Natl Acad Sci U S A. 2015;112:815-20.

76. Heliconius Genome Consortium. Butterfly genome reveals promiscuous exchange of mimicry adaptations among species. Nature. 2012;487:94-8.

77. Streicher JW, Devitt TJ, Goldberg CS, Malone JH, Blackmon H, Fujita MK. Diversification and asymmetrical gene flow across time and space: lineage sorting and hybridization in polytypic barking frogs. Mol Ecol. 2014;23:3273-91. 
78. Seehausen O. Hybridization and adaptive radiation. Trends Ecol Evol. 2004; 19:198-207.

79. Leduc-Robert G, Maddison WP. Sequence reads for Habronattus transcriptomes. 2017. https://www.ncbi.nlm.nih.gov/bioproject/ PRJNA421554

Ready to submit your research? Choose BMC and benefit from:

- fast, convenient online submission

- thorough peer review by experienced researchers in your field

- rapid publication on acceptance

- support for research data, including large and complex data types

- gold Open Access which fosters wider collaboration and increased citations

- maximum visibility for your research: over $100 \mathrm{M}$ website views per year

At BMC, research is always in progress.

Learn more biomedcentral.com/submissions 